\title{
Nanotechnology and Nanoscience - From Past Breakthroughs to Future Prospects
}

\author{
Jernej Štremfelj, Franc Smole \\ University of Ljubljana, Faculty of Electrical Engineering, Ljubljana, Slovenia
}

\begin{abstract}
Nanoscience and nanotechnology are already improving our lives in numerous ways. The aim of this paper is to give an insight into the vast array of their potential future uses, as well as current applications, and present the major breakthroughs, which made their development possible. A special section is reserved for the development in the field of microelectronics, which is facing numerous challenges due to the downsizing of devices to the nanometre level. Current situation in microelectronics industry and predictions for the next few years are presented. Furthermore, the use of nanotechnology and future prospects in the fields of medicine, energetics, environmental protection and transport are described. A significant part of this paper is devoted to the field of electronics and information technology, where some potential nanotechnological solutions for the challenges of microelectronics are implied. The use of carbon nanotubes in logic circuits and memory applications is presented. The basic principle of single-electron transistor is also described. Basic concepts of the use of spintronics in magnetoresistive random access memory (MRAM) structures are explained. Memristor is also presented as an important future prospect. In the last part, the investments in nanotechnology and nanoscience under the funding programmes of European Union are presented, followed by some predictions of these fields'future development. However, the review paper focuses only on positive effects of the use of nanotechnology, and thus does not discuss its possible negative impact on public health and environment.
\end{abstract}

Keywords: nanotechnology; nanoscience; microelectronics; carbon nanotubes; quantum dots

\section{Nanotehnologija in nanoznanost - od preteklih dosezkov do obetov za prihodnost}

\begin{abstract}
Izvleček: Nanoznanost in nanotehnologija že izboljšujeta naše življenje na različne načine. Namen članka je podati vpogled v širok nabor potencialnih področij njune uporabe tako v današnjem času, kot tudi v prihodnosti in predstaviti pomembnejša odkritja, ki so omogočila razvoj tega področja. Posebno poglavje je namenjeno razvoju na področju mikroelektronike, ki se zaradi manjšanja dimenzij na nanometrski nivo sooča s številnimi izzivi. Predstavljena je trenutna situacija v mikroelektronski industriji in obeti za naslednjih nekaj let. V nadaljevanju je predstavljena uporaba nanotehnologije in obeti za prihodnost na področjih medicine, energetike, varovanja okolja in transporta. Pomemben del članka je namenjen področju elektronike in informacijskih tehnologij, kjer so predstavljene nekatere potencialne nanotehnološke rešitve za izzive mikroelektronike. Predstavljena je uporabnost ogljikovih nanocevk v logičnih vezjih in pomnilniških strukturah. Razloženo je osnovno delovanje enoelektronskega tranzistorja. Podani so koncepti uporabe spintronike v pomnilniških strukturah MRAM (magnetoresistive random access memory), kot pomemben obet za prihodnost pa je predstavljen tudi memristor. V zadnjem delu so navedena sredstva, ki jih Evropska Unija v okviru svojih programov financiranja namenja za razvoj nanotehnologije in nanoznanosti. Navedenih je tudi nekaj napovedi glede razvoja opisanih področij v prihodnosti. V članku so predstavljeni le pozitivni vplivi uporabe nanotehnologije, medtem ko analiza morebitnih negativnih vplivov na okolje in zdravje ljudi ni vključena.
\end{abstract}

Ključne besede: nanotehnologija; nanoznanost; mikroelektronika; ogljikove nanocevke; kvantne pike

*Corresponding Author's e-mail:js8675@student.uni-lj.si

\section{Introduction}

Nanotechnology focuses on developing materials, structures and systems by manipulating matter on the
1-100 nm scale [1], [2]. However, the final objective does not necessarily have to be nanodimensional. It is of most importance that new properties, which occur 
at the nanometre scale are being taken advantage of [1]. The role of nanoscience is to pave the way for nanotechnology by studying those phenomena [2]. The fact is that the nanometre world behaves a little differently as one would expect based on one's visible and also micrometre world experience. Physical, mechanical, chemical, electrical and numerous other properties of particles are being completely changed as quantum effects begin to rule their behaviour [1], [3]. Those effects are studied by an important branch of modern physics, called quantum mechanics, which was developed after the year 1900 [1].

One of the fascinating results of quantum effects at the nanoscale is that the particle properties are changing with its dimensions. Therefore, material properties can be fine-tuned by changing the size of the particles. Thus, they can for example be labelled with fluorescent colours, which is useful for their identification [3].

An interesting example, which illustrates those unique properties is gold. A metal, which typically has a distinctive yellow colour, occurs as red or purple at the nanoscopic scale (Fig. 1). The reason for this phenomenon is that the movement of electrons is confined at the nanoscale dimensions, which gives golden nanoparticles a different light response, compared to bigger particles. Their small dimensions and special optical properties make them increasingly useful in medicine. They are being accumulated selectively in cancer cells, which allows precise laser destruction of tumour, without harming healthy cells [3].

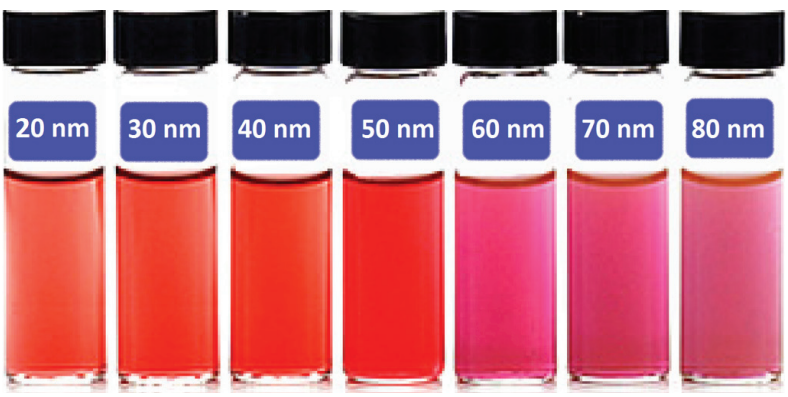

Figure 1: Light response of gold nanoparticles with different diameters. Reprinted with modification (cropping) from [4]. Copyright 2016-2020 Phornano Holding $\mathrm{GmbH}$.

Another quantum effect that is completely contradictory with the laws of classical physics is quantum tunnelling through a potential barrier [3], [1]. In 1981, a scanning tunnelling microscope was invented on its basis and brought a Nobel Prize in physics to its inventors [5], [6].
All of the aforesaid examples certainly give us an explanation why developers in many completely different areas of modern technology strive for miniaturisation. A simple thought experiment, which is depicted in Fig. 2, leads to additional arguments. Let us imagine a $1 \mathrm{~cm}^{3}$ cube. Its surface area is therefore $6 \mathrm{~cm}^{2}$. If we divide it into 1000 smaller cubes with $1 \mathrm{~mm}^{3}$ volume, we get a total surface area of $6000 \mathrm{~mm}^{2}$ or $60 \mathrm{~cm}^{2}$. If we continue with this procedure to the nanometre scale, we get $10^{21}$ cubes with volume of $1 \mathrm{~nm}^{3}$ and surface area of $6 \mathrm{~nm}^{2}$ each. By adding their surface areas, we get an astonishing value of $6 \mathrm{~km}^{2}$. Therefore, smaller particles have exceptionally large active surface area compared to their volume. Consequentially, there is more area for contact between particles, which increases their reactivity [3].

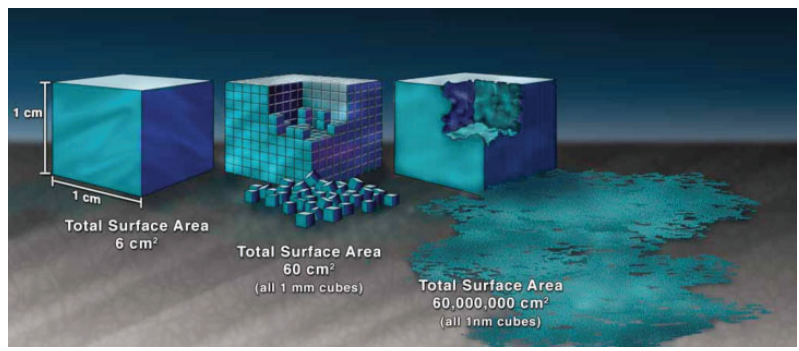

Figure 2: Increase in total surface area, achieved by diminishing particle size. Reprinted from [3]. Licensed under CC BY 3.0 license.

\section{Microelectronics}

However, when speaking about decreasing dimensions, especially electronic engineers firstly think about the famous Moore's law. Most electronic devices are downsizing especially due to their better functionality and compactness, and not because of fascinating nanodimensional phenomena. In addition, the devices are becoming cheaper with more chips being made on one silicon wafer. This development is made possible by downscaling of the basic components of integrated circuits - the transistors. The discovery of this element can be counted as the beginning of the microelectronic industry. This achievement was accomplished in 1947 in Bell Laboratories by William Shockley, John Bardeen and Walter $\mathrm{H}$. Brattein, who were awarded Nobel Prize in physics, nine years later [1], [7].

Although the first transistor was a point-contact transistor (Fig. 3), it represented a basis for the development of the first germanium bipolar transistor, based on two pn-junctions, which was conceived in year 1948 by Shockley and fabricated in 1950 . Four years 


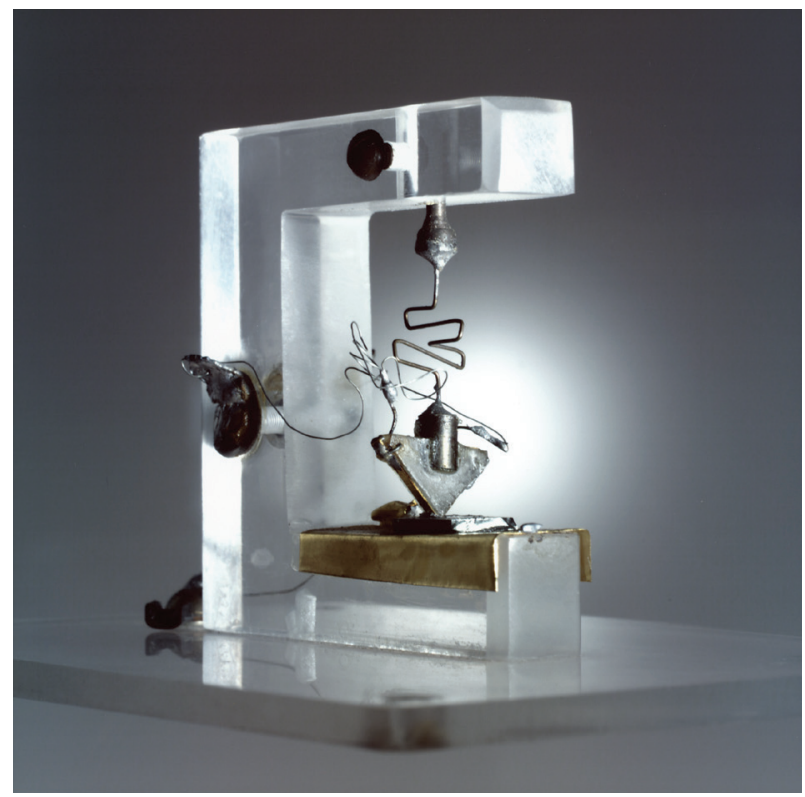

Figure 3: First transistor. Reprinted from [8]. Copyright 2020 Nokia. later, Gordon Teal from Texas Instruments made the first silicon version [9]. Next big breakthrough happened in year 1958, when Jack Kilby realised integration of elements on the same germanium substrate (Fig. 4.c). In 1959, Robert Noyce integrated also the connections, this time on a silicon substrate, and therefore laid the foundations for integrated circuit development [10]. In the same year, Dawon Kahng and Martin John Attala made the first metal-oxide semiconductor field-effect transistor (MOSFET) by growing a silicon dioxide $\left(\mathrm{SiO}_{2}\right)$ layer on silicon wafer (Fig. 4.b) [11]. This was the first compact transistor, whose structure made possible the miniaturisation to the dimensions, used in today's complementary metal-oxide semiconductor (CMOS) integrated circuits [12]. The mentioned inventions are presented in Table 1 in chronological order. Two of them are also depicted in Fig. 4, which shows the progress in the design principles of electronic components and integrated circuits through years. a)

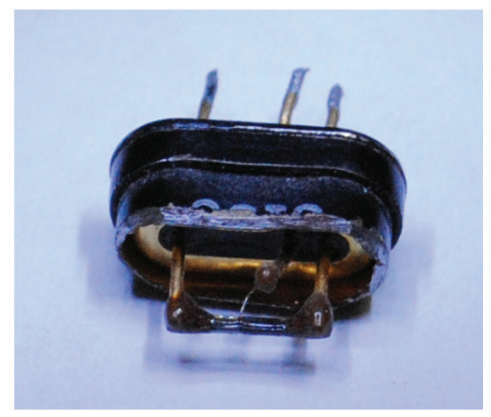

b)

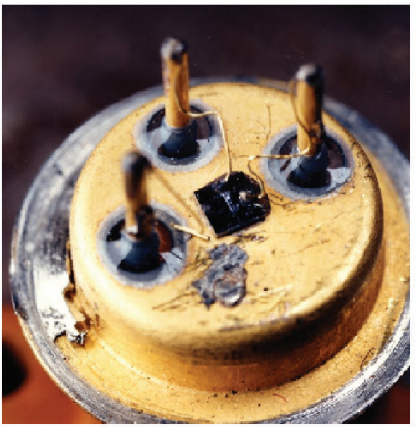

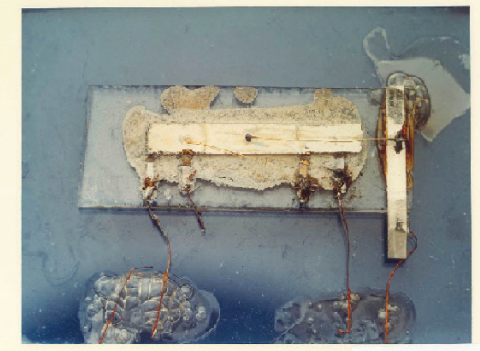

P600032

c)

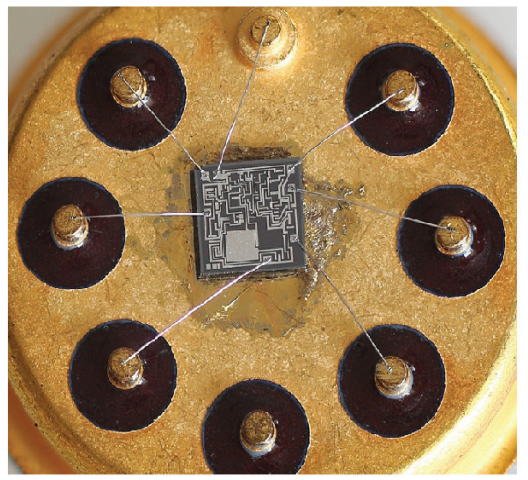

d)

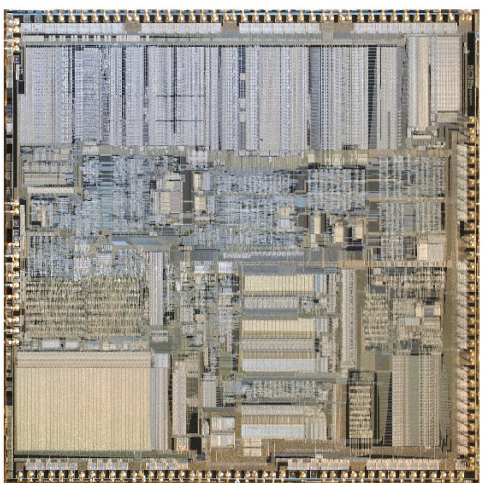

e)

Figure 4: a) Silicon NPN grown-junction bipolar transistor of type ST2010, manufactured in 1961. Reprinted with modification (cropping) from [13]. Licenced under CC BY-SA 3.0. Author: David Forbes; b) First MOSFET, fabricated in Bell Laboratories in 1959. Reprinted from [14]. Copyright 2021 Nokia; c) First integrated circuit, fabricated in Fairchild Semiconductor in 1959. Reprinted from [15]; d) uA741 operational amplifier, made by Fairchild Semiconductor in 1969. Reprinted with modification (cropping) from [16]. Licenced under CC BY-SA 4.0. Author: Jay Philippbar; e) Die image of Intel A80386DX-20 32-bit microprocessor, introduced in 1987. The integrated circuit consisted of 275000 transistors [17]. Reprinted from [18]. Licenced under CC BY-SA 3.0. 
Table 1: Important inventions, which made possible the development of microelectronics industry

\begin{tabular}{|c|c|c|}
\hline \multicolumn{1}{|c|}{ Inventor } & Year & Discovery \\
$\begin{array}{c}\text { W. Shockley, } \\
\text { J. Bardeen, } \\
\text { W. H. Brattein }\end{array}$ & 1947 & First transistor \\
\hline $\begin{array}{c}\text { W. Shockley, } \\
\text { G. Teal, } \\
\text { M. Sparks }\end{array}$ & 1950 & $\begin{array}{c}\text { First germanium bipolar } \\
\text { transistor }\end{array}$ \\
\hline G. Teal & 1954 & $\begin{array}{c}\text { First silicon bipolar } \\
\text { transistor }\end{array}$ \\
\hline J. Kilby & 1958 & $\begin{array}{c}\text { Integration of elements } \\
\text { on germanium substrate }\end{array}$ \\
\hline R. Noyce & 1959 & $\begin{array}{c}\text { Integration of elements } \\
\text { and connections on } \\
\text { silicon substrate }\end{array}$ \\
\hline $\begin{array}{c}\text { D. Kahng, } \\
\text { M. J. Attala }\end{array}$ & 1959 & First MOSFET \\
\hline
\end{tabular}

In 1965, Gordon E. Moore predicted that the number of components per integrated circuit would double every year in his article for the journal »Electronics« [19]. In 1975 , he modified his assumption a bit, and predicted doubling approximately every two years [20]. 45 years later, we can conclude that his predictions were correct, which can be observed in Fig. 5. Achieving predicted miniaturisation became the driving force of microelectronics development.
In the middle of the 1980s, the minimal gate length of the MOSFET reached $1 \mu \mathrm{m}$, whereas at the turn of the millennium the typical dimensions were already at around $150 \mathrm{~nm}$ [21]. In 2005, the $65 \mathrm{~nm}$ technology was introduced, five years later the main manufacturers already produced chips in the $32 \mathrm{~nm}$ technology [1]. At this point, it is necessary to stress that inconsistencies between technology node names and actual transistor dimensions occurred through the years. The dimensions, stated in technology node name, are a consequence of International Technology Roadmap for Semiconductors (ITRS) [22] and its successor International Roadmap for Devices and Systems (IRDS) guidelines [23], which predict the development in this field for the next fifteen years. Until the mid-1990s, the technology node dimensions were consistent with the gate length of MOSFETs [24], while today they do not correspond to any of actual dimensions, but only reflect the general technology progress [25]. That being the case, the Intel's $250 \mathrm{~nm}$ technology transistors had gate length of $200 \mathrm{~nm}$, while its $180 \mathrm{~nm}$ technology transistors from a year later only $130 \mathrm{~nm}$. The trend of more aggressive gate length scaling lasted to the year 2007, when Intel reached the gate length of $25 \mathrm{~nm}$ with its $45 \mathrm{~nm}$ technology node. At that time, the gate length downscaling stalled for few years [26]. Miniaturisation to such small dimensions brought numerous disadvantages, which more than ten years ago indicated that CMOS technology would not be able to achieve further progress only

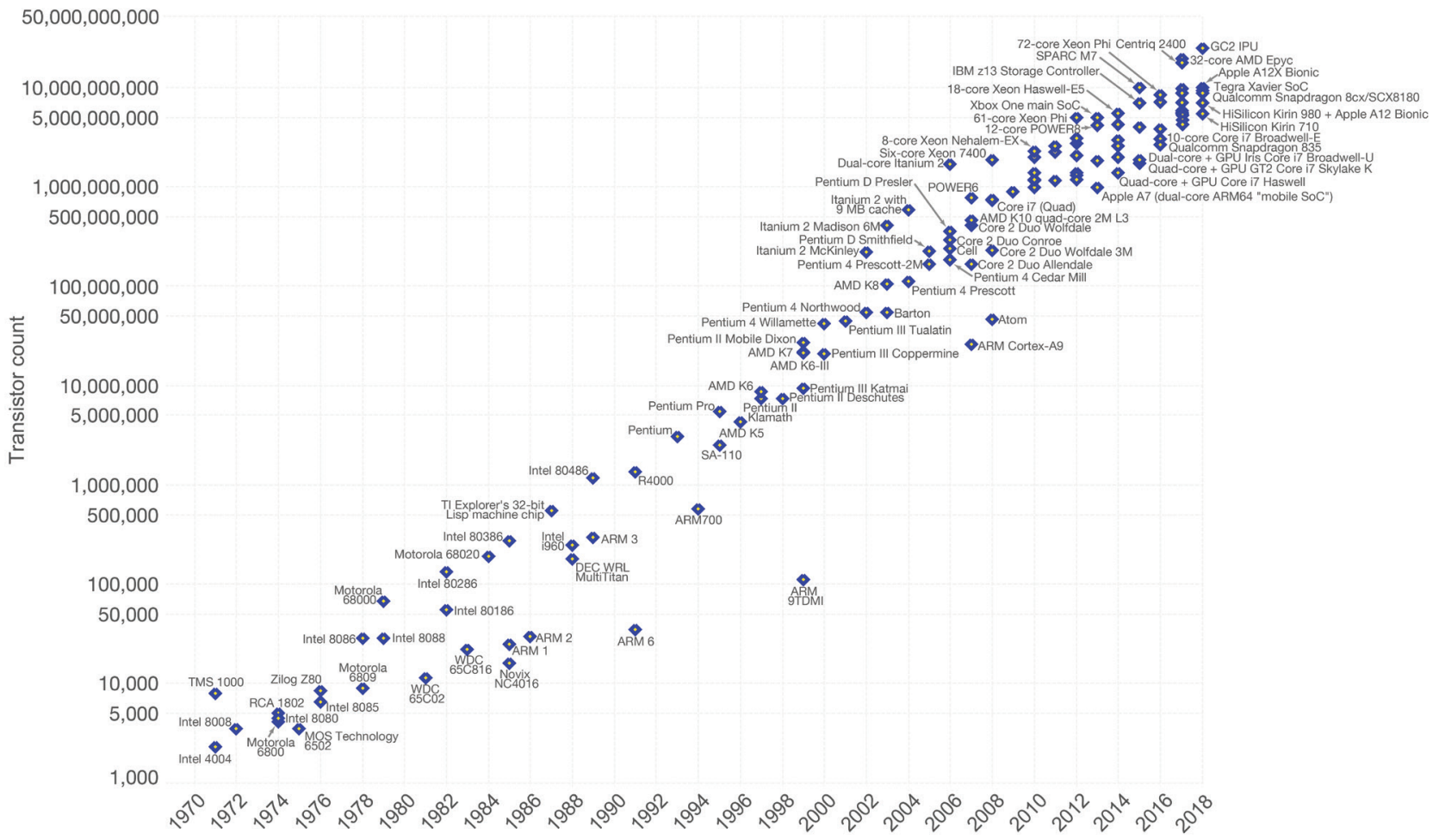

Figure 5: Number of transistors per integrated circuit between years 1971 and 2018. Reprinted with modification (cropping) from [29]. Licensed under CC-BY-SA 4.0 license. Author: Max Roser 
by downsizing planar transistors. The MOSFET channel dimensions had decreased to such an extent that the voltage applied between the drain and the source began to cause significant subthreshold leakage, which increased static power consumption in CMOS circuits. As a solution, the first three-dimensional (3D) MOSFET - fin field-effect transistor (FinFET) entered mass production in 2011, within the $22 \mathrm{~nm}$ technology node [27].

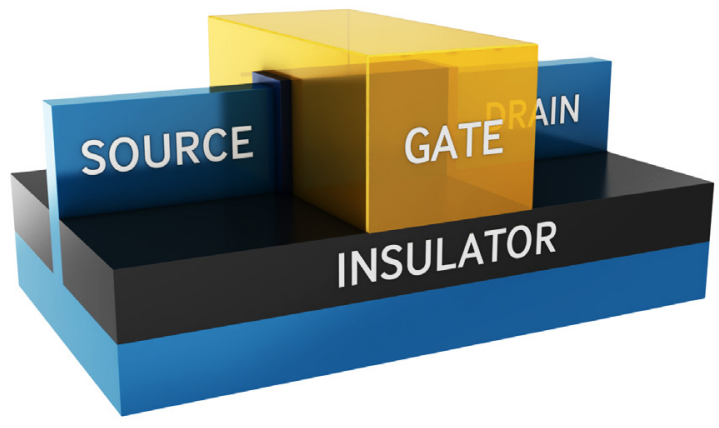

Figure 6: Visualisation of FinFET. Reprinted from [28]. Copyright 2010-2020 Samsung.

In this type of transistor, depicted in Fig. 6, the channel is vertically raised above the substrate and surrounded with the gate on three sides, which limits the mentioned current leakage. However, FinFET also has its disadvantages. By planar transistors, the channel width can be flexibly determined in order to achieve the desired current capabilities. Higher width-to-length ratio results in higher transistor current at certain gate-tosource voltage in the saturation region. It also brings higher transconductance of the transistor, which gives higher ratio between changes in drain current and gate-to-source voltage. By FinFET, the effective channel width cannot be so unrestrictedly set. It is equivalent to

$$
2 \cdot h_{f i n}+w_{f i n}
$$

where $h_{\text {fin }}$ denotes the channel height and $w_{\text {fin }}$ represents the channel width. The height is limited with manufacturing process, while changing the width-toheight ratio is undesirable due to the worsening of characteristics. That issue was solved by developing FinFET with multiple fin structures [1]. This version of FinFET is also being used in the latest $5 \mathrm{~nm}$ technology [30], whose mass production was started by Taiwan Semiconductor Manufacturing Company (TSMC) and Samsung in 2020 [31].

Nevertheless, the way for the mass production is paved by prior research and development, which at the same time give us a look into the future prospects. On that basis, it is assumed that FinFET is soon going to be replaced with new solutions. The developers found additional room for improvement in the fact that FinFET's bottom side was still connected to the body of the silicon, which meant that the subthreshold leakage could be further reduced. The idea was realised by the development of a transistor with the gate surrounding the channel on all sides - gate all-around field-effect transistor (GAAFET) [27].

The result of GAAFET development was firstly a transistor with the channel region in the shape of a very narrow nanowire. However, the small channel dimensions did not provide sufficient currents and consequentially switching speeds, which was soon solved by stacking nanowires on the top of each other (Fig. 7 - GAAFET). Unfortunately, this approach also brought several limitations. Similar as by FinFET, the stack's height was limited. Furthermore, additional nanowires increased the device's capacitance and thus slowed the transistor's switching speed. Another downside was the complex manufacturing of very narrow nanowires, which could lead to structure irregularities [27].

The discussed problems were diminished by developing a transistor with nanosheets (Fig. 7 - MBCFET), which is, according to Samsung, going to be used in the $3 \mathrm{~nm}$ technology, whose mass production is predicted to begin in the next years [32]. This is an improved version of the aforementioned GAAFET, with stacked thin sheets of silicon instead of nanowires. Thus, the effective channel width is increased, while the leakage current is still limited. Moreover, the variable sheet width enables the channel width flexibility, which is not the case by FinFET [27].

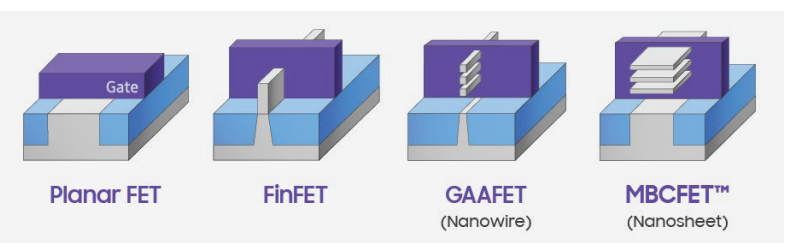

Figure 7: Evolution of Samsung's field-effect transistors. Reprinted from [33]. Copyright 2010-2020 Samsung.

With all the described improvements, the validity of the Moore's law, whose end has been foreseen by many, certainly extended for at least a decade. Nonetheless, all mentioned solutions are still based on the elementary version of silicon MOSFET, where the photolithography with all its limitations remains the main technological process. The main problem regarding photolithography is that at the nanoscale dimensions, the diffraction of light causes significant random manufacturing variations, which can result in unpredictable behaviour of elements [1]. Nevertheless, we are witnessing a fast development also in this field. 
In the second half of 2019, the extreme ultraviolet lithography (EUVL) at 13,5 $\mathrm{nm}$ wavelength succeeded the deep ultraviolet lithography using excimer argon fluoride (ArF) laser at $193 \mathrm{~nm}$ wavelength, in mass production of some $7 \mathrm{~nm}$ technology integrated circuits [34], [1]. Despite the promising predictions of using even shorter wavelengths, which could be made possible by the development of beyond extreme ultraviolet lithography (BEUVL) [35], it is quite probable that downscaling, using only lithography processes will soon come to an end.

Another issue, brought by small dimensions of integrated circuits and high transistor density, is cooling. One of its consequences is the stall of the processor frequency, which has not significantly improved for approximately a decade and remains below $4 \mathrm{GHz}$ in most cases. A potential solution for the near future is in using other, more efficient semiconductor materials as silicon, for example indium-gallium arsenide (InGaAs) [27].

Regardless of all foregoing solutions, it is inevitable that electronics industry is going to face essential changes in the future. It will be necessary to find alternatives to the CMOS technology, which are most likely going to be based on the aforementioned nanodimensional phenomena. Downscaling brought the dimensions almost to the atomic level and consequently gave us a completely different perspective of future technological development. New approaches to the mentioned problems, using new materials are being researched. Many studies already focus on the self-assembly of nanostructures on the atomic level [1].

\section{Atoms}

The idea of manipulating single atoms stirred already the imagination of ancient Greek philosophers. In the fifth century before Christ, philosophers Democritus and Leucippus, who were also the founders of the Greek philosophical school of atomism [36], stated that everything was composed of atomos (Greek word for "unbreakable"), which were indivisible. They claimed that those particles were solid and homogenous but varied in size, shape and weight. Between them, there was only empty space. Later on, their ideas came in for criticism and disapproval from other philosophers and were also considered atheistic by Christians [37].

Scientific establishing of the atomic theory began in the 17. century, when British scientist Robert Boyle proved the inverse relationship between the pressure of a gas and its volume, which is known as Boyle's law. The pressure in a container of gas is a consequence of the atoms' collisions with the container walls, which are more significant at a smaller volume of container. At the end of the 18. century, a French chemist Joseph Louis Proust empirically discovered that the ratio between different elements in a chemical compound always remains the same, without being affected by the way of its preparation, which is consistent with the Democritus' concept of indivisibility. His theory was later expanded by John Dalton, who figured out that the molecules consisted of fixed number of different atoms and therefore laid the foundations for the modern atomic theory [37].

In the 19. century, the question arose, what are the atoms composed of. Joseph John Thomson was one of the scientists, who tried to answer it. He experimented with a closed glass tube with almost no air inside. With high voltage applied across two metal electrodes in it, he produced a visible ray and found out that the ray deflected in presence of electric or magnetic field. On the basis of the deflection and magnetic field measurements, he concluded that the particles in this ray were significantly lighter than atoms. In addition, he observed that they were attracted by positive charge and repelled by negative, which indicated their negative charge. He got similar results when using electrodes of other metals, which lead him to a conclusion, that these particles were present in all atoms [38]. Therefore, he showed that the atoms were not indivisible and proved the existence of electrons [39]. In 1904, he proposed a model of atom, depicted on Fig. 8.a, where the electrons were embedded in positively charged mass, making the atom electrically neutral. Next important breakthrough in studying electrons' properties was achieved in 1909 by Robert Andrews Millikan, who found out the value of charge and mass of a single electron. However, the form of the atoms, especially the positively charged part, was still not properly explained [38].

The inaccuracy of by then proposed atom models was proved by Ernest Rutherford in 1911, even though he initially tried to confirm their correctness. He, Hans Geiger and Ernest Madsen conducted an experiment where they directed a beam of positively charged alpha particles to thin gold foil and observed their deflection. Assuming the Thomson's model, which implied distribution of positive charge over the entire atom, was correct, they expected little or no deflection of particles. However, whereas most of the particles really passed through the foil without any deflection, some of them were significantly diverted. On that basis, Rutherford concluded that most of the atom's volume consisted of empty space, whereas at the centre of atom, there was a small, positively charged nucleus. He proposed a new model of atom, depicted on Fig. 8.b, with the electrons orbiting around the nucleus [38], [39]. Later, he discovered that all elements' nuclei contained hydro- 


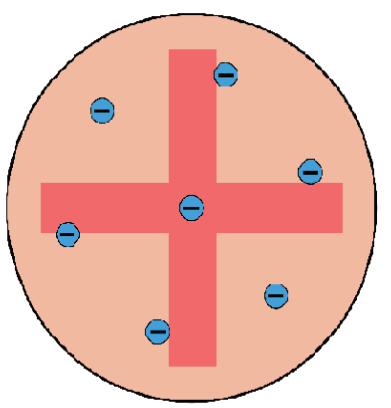

a)

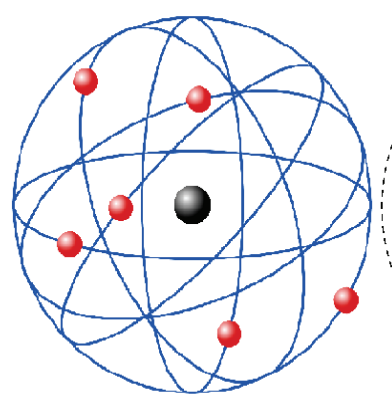

b)

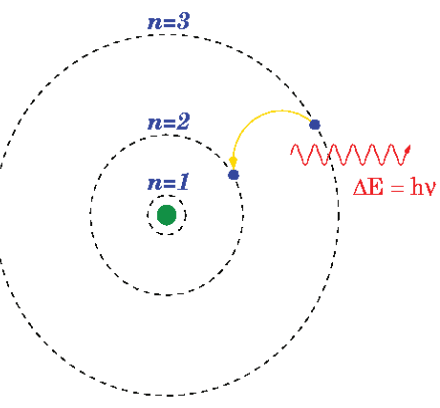

c)

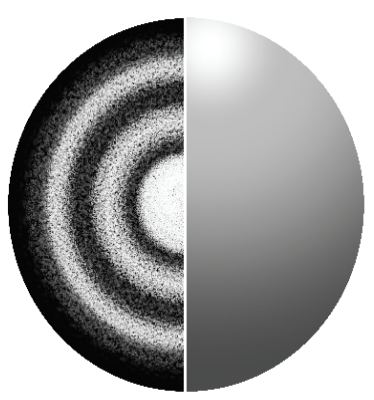

d)

Figure 8: a) Thomson's atomic model, called also "The plum pudding model". Reprinted from [40]. Licenced under CC BY-SA 4.0.; b) Rutherford's atomic model. Reprinted from [41]. Licenced under CC BY-SA 3.0.; c) Bohr's atomic model. Reprinted from [42]. Licenced under CC BY-SA 3.0.; d) Schrödinger's atomic model, called also"The quantum mechanical model" or "Wave model". Reprinted from [43]. Licenced under Pixabay License.

gen nuclei - positively charged subatomic particles. He named them protons [38].

In 1913, Niels Bohr found out that the movement of the electrons in orbits with arbitrary radii, as proposed in Rutherford's model, was unstable. According to the classical physics, electrons would emit electromagnetic radiation when orbiting and consequently lose energy. Therefore, their orbits' radii would diminish, so they would spiral towards the nucleus. Based on the findings of Max Planck and Albert Einstein, who postulated that the energy of radiation could have only discrete values, Bohr stated that the angular momentum of the electron was also quantised. Due to the quantisation, the orbits had fixed radii and energies. In order to jump to another orbit, the electron had to emit or absorb the energy equal to the difference of two orbits' energies [44]. The Bohr's model of atom is depicted on Fig. 8.c.

However, the Bohr's theory did not prove to be entirely correct. His model was based on the hydrogen atom, and could not explain the emitted spectrum of atoms with more electrons. Even hydrogen's spectrum was not adequately explained with Bohr's energy levels. Its individual spectral lines proved to be divided into more, closely spaced ones, which showed the existence of additional energy states [44], [45].

In the early 1920s, the scientists started to develop a theory, where the matter was assumed to have both particle and wave characteristics. In 1923, Louis Victor de Broglie stated that the electrons should also be considered that way [44].

In 1926, Erwin Schrödinger developed an equation, which represented the foundation of the quantum mechanics. It described the form of wave functions, whose values at a given point of time and space gave the information about the probability of the particle, being at that point. He applied and also successfully solved it for the hydrogen atom [46], [47]. Therefore, he proposed the quantum mechanical model of atom (Fig. 8.d), where the electrons were treated as waves. Instead of the exact location of an electron, only the probability of the electron, being in a given region could be determined [48]. The Schrödinger's model of atom is still accepted as the most accurate one [39].

Nevertheless, the structure of atomic nucleus was not yet entirely understood. It was known that it contained protons, but its mass indicated the existence of additional building blocks [49]. In 1932, James Chadwick observed the reaction between alpha particles and beryllium atoms. Neutrally charged particles with approximate mass of proton were emitted. These particles were named neutrons [50]. This finding also explained the existence of isotopes - chemically indistinguishable atoms with different atomic masses, discovered by Frederick Soddy about twenty years before. The isotopes of a same element have different number of neutrons and consequentially different atomic masses, whereas their chemical properties remain the same, because of the same number of protons [38], [51].

Another quantum phenomenon that is important for understanding the atom's structure is the electron spin. It was experimentally discovered by Otto Stern and Walther Gerlach in 1922. They directed a beam of electrically neutral silver atoms through an inhomogeneous magnetic field. On the basis of the classical physics and the assumption that the electrons would act as magnetic dipoles, they expected that the atoms would be deflected in different directions, based on the magnetic dipole moments' orientations, giving a random and continuous distribution on the screen. However, the atoms were deflected only in two directions. That result clearly indicated that electrons could exhibit only two possible, antiparallel orientations, which could not 
be explained by classical physics. The reason for that result was in the electron spin, which could have two possible values. Up and down [48], [1].

Three years after the abovementioned experiment, Wolfgang Ernst Pauli discovered that only two electrons could be located in the same orbital or energy level. In addition, they had to have the opposite spin. Hence, the electrons repel each other not only because of the charge, but also due to the parallel spins [1]

Another interesting empirical discovery was made by Friedrich Hund, who found out that the electrons in ground state always occupy the maximum number of empty orbitals. Therefore, if more energetically equivalent orbitals are available, they occupy the empty ones, rather than join an electron in a half-occupied orbital. Such arrangement of electrons is more stable [1].

Since that time, our understanding of the atomic world improved even more. However, the described transition from classical mechanics to quantum mechanics, which crucially influenced the atomic theory, represents one of the most important advances in the history of physics. All the mentioned findings made many achievements of the nanotechnology possible. The electron spins can for example be used as qubits in quantum computing. The electron and also nuclear spin of phosphorus donor in silicon proved highly appropriate for such use [52], [53], [54].

\section{A half century of nanotechnology}

The outstanding potential of the abovementioned possibilities fascinated an American physicist Richard Feynman in the 1950s. His prophetic speech »There's Plenty of Room at the Bottom«, which he held at the annual banquet of the American Physical Society in 1959 , could be counted as the beginning of the history of nanotechnology. Therein, he pointed out that the technology process miniaturisation to the atomic level was completely realisable according to the laws of physics and predicted that future technology was going to be based on rearranging the atoms as desired. He talked about the bottom-up approach, which represented an alternative to the top-down approach, which has been driving the miniaturisation in the field of microelectronics, according to the Moore's law, for many more years. Feynman motivated the audience with numerous challenges, like for example writing the entire Encyclopaedia Britannica on a pinhead, or making an electrical motor, smaller than $0.256 \mathrm{~cm}^{3}$ and also offered a pair of $1000 \$$ prizes. Some of the challenges were already realised in months after the speech, which made it clear that his predictions were going to come true even sooner than he expected [37].

The term »nanotechnology« was first used in 1974 by a Japanese scientist Norio Taniguchi in a paper about the technological concepts on the nanometre level. He stated that atoms and molecules with the dimensions of 0.1-0.2 $\mathrm{nm}$ are the smallest particles in the processing of materials. In addition, he defined the separation, consolidation and deformation of materials by single atoms or molecules as a main part of the nanotechnology [55].

A very important breakthrough in further nanotechnology and nanoscience development was achieved in 1981 by the scientists of the company International Business Machines (IBM) Zürich, who invented the aforementioned scanning tunnelling microscope [5]. Five years later, the atomic force microscope was invented in the same company and became the most important tool for observing and manipulating material on the atomic level [56]. In the following years, the increasingly efficient computing systems enabled progressively demanding simulations, which, alongside with the experimental work, lead to fast development. In 1989, another scientific team from IBM managed to align 35 atoms of xenon in the form of letters »/BM« (Fig. 9) [57].

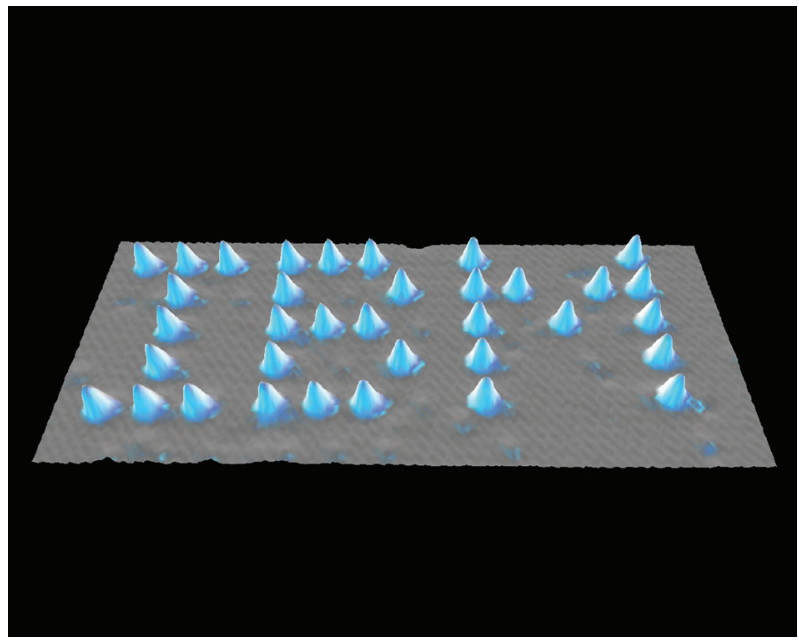

Figure 9: Thirty-five xenon atoms, arranged in the form of "IBM". Image originally created by IBM Corporation.

Another very important discovery had been made four years before by scientists Robert F. Curl, Harold W. Kroto and Richard E. Smalley, who discovered the carbon allotrope - buckminsterfullerene $\left(C_{60}\right)$ [58]. As a consequence, special structures of fullerene - the carbon nanotubes (CNTs) were discovered in 1991 [59]. 


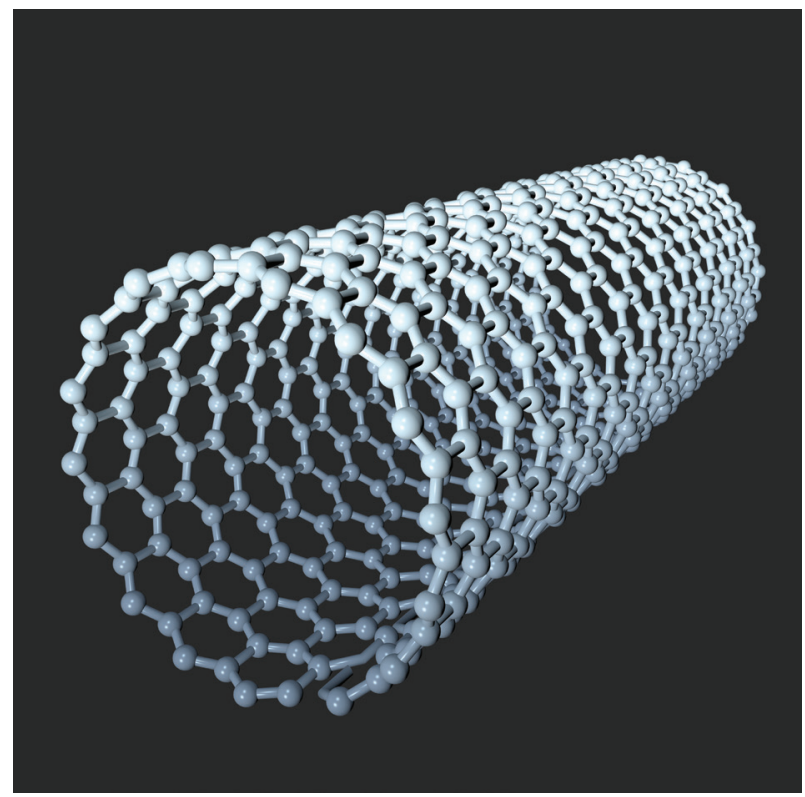

Figure 10: Visualisation of a CNT. Reprinted from [60]. Copyright 2000-2020 Dreamstime.

A structure of a CNT can be imagined as a graphene sheet, rolled into a hollow cylinder, as shown in Fig. 10. The carbon atoms are connected by sigma $(\sigma)$ bonds, which are the strongest type of covalent chemical bonds. This makes CNTs the strongest fibres. Topological defects in their structure, like pentagons and heptagons, embedded in the hexagonal lattice, enable their termination, as well as formation of joints and toroidal or spiral shaped nanotubes. In addition to the mechanical ones, they also have outstanding electrical, chemical, optical, magnetic and thermal properties. Their diameter varies between $0.4 \mathrm{~nm}$ and $3 \mathrm{~nm}$ for single-wall CNTs or up to $100 \mathrm{~nm}$ for outer walls of multi-wall CNTs. They can be metallic or semiconducting. Researches have shown their potential as sensors, actuators, batteries, fuel cells, capacitors and field-emission devices, which makes them one of the most promising materials in the field of nanotechnology [1].

The studies of semiconductor nanocrystals also lead to the development of quantum dots [61]. These are small, in most cases semiconductor structures, with the dimensions that are comparable or smaller than the Fermi wavelength, which is around a nanometre for metals and few dozen nanometres for semiconductors. Therefore, the movement of electrons is restricted in all three dimensions, which results in discrete energy states of electrons that completely change the material properties (Fig. 11) [1].

What is more, the small dimensions bring higher reactivity to the material, because of more atoms on the surface, which can interact with the environment.

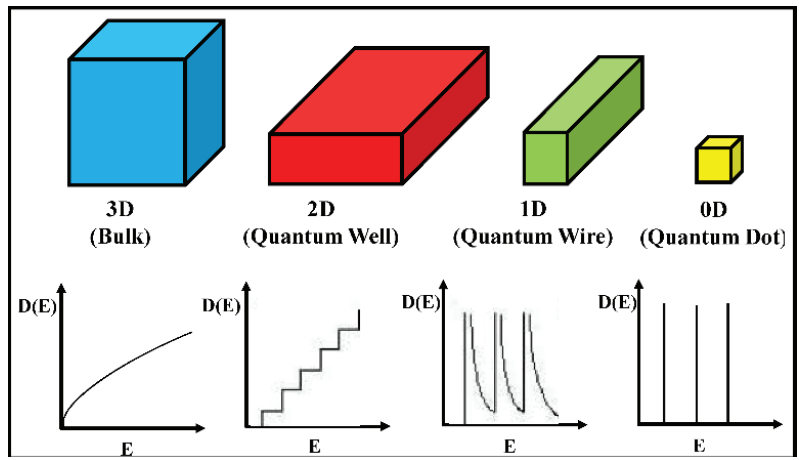

Figure 11: Diagram of density of states for different forms of semiconductors. Discrete energy states can be observed in case of quantum dots. Reprinted from [62]. Licensed under CC BY-NC-SA 3.0 license.

Quantum dots can be used as charge islands in the circuits based on the Coulomb blockade [1]. Additionally, their exceptional optical properties make them potentially useful in lasers, photodetectors [63], displays [64], solar cells [65] and also as biological markers. The return of excited electrons to the ground state produces light emission. Therefore, by making sure that for example a semiconductor quantum dot stops on a cancer cell and is appropriately illuminated, a tumour can be detected [1].

In the 1990s, the progress of nanotechnology continued at an increasingly high rate. In 1992, nanostructured catalytic materials MCM-41 and MCM-48 were discovered. They are still being heavily used in refining crude oil and also in medicine [66], [67].

Seven years later, Lee and Ho from American university Cornell managed to assemble molecules of $\mathrm{Cu}(\mathrm{CO})$, $\mathrm{Fe}(\mathrm{CO}), \mathrm{Cu}(\mathrm{CO})_{2}$ and $\mathrm{Fe}(\mathrm{CO})_{2}$ from individual iron (Fe) and copper (Cu) atoms and carbon oxide (CO) molecules, by using a scanning tunnelling microscope [68].

In the same year, Chad Mirkin invented dip-pen nanolithography and so introduced one of the alternatives to the before described photolithography. As the name suggests, the material is deposited on the surface by an atomic force microscope tip, similarly as by writing with a pen on the paper (Fig. 12) [69]. Therefore, a mask is not necessary, which is a crucial benefit [1].

In the following years, nanotechnological solutions started to make their way to commercial products. Scratch-resistant car bumpers, antibacterial socks, faster-recharging batteries, electronic devices with improved displays and similar products began to appear. The scientific achievements in this field were also increasingly frequent [67]. 


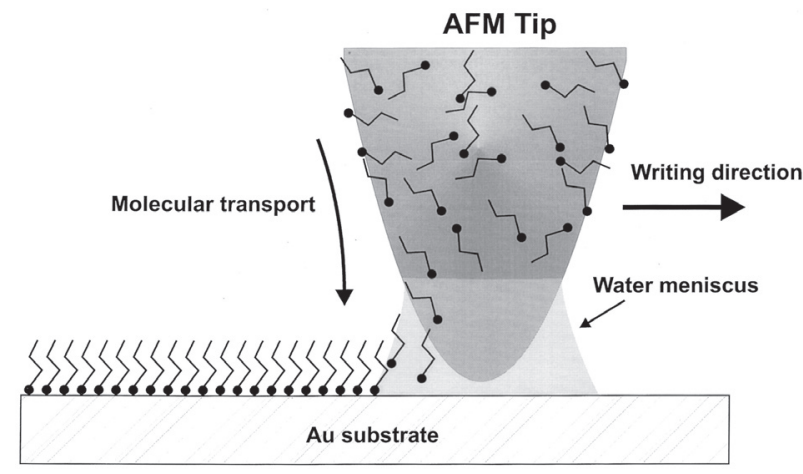

Figure 12: Writing principle of dip-pen nanolithography. From [69]. Reprinted with permission from AAAS.

In 2003, the scientists at Rice University developed gold nanoshells, which at the right dimensions absorb nearinfrared light and can therefore be used for discovery, diagnosis and also treatment of breast cancer [70], [67].

Two years later, Barish, Rothemund and Winfree from the California Institute of Technology made deoxyribonucleic (DNA) crystals that perform operations of copying and counting by self-assembling and hence demonstrated the potential of algorithmic self-assembly for being used in creating complex nanoscale patterns [71]. Self-assembly of smaller components into larger and more complex ones due to intermolecular forces, similar as in nature, became one of the most promising fields of research in nanotechnology [1]. In 2010, Seeman and his team from New York University made a 3D self-assembling DNA structure, whose construction can be programmed by putting small cohesive sequences on ends of the patterns [72].

Another unique achievement was made by IBM in the same year. Using a nanometre-sized silicon tip, they created a $3 D$ relief world map with the dimensions of $22 \mu \mathrm{m}$ by $11 \mu \mathrm{m}$ in two minutes and twenty-three seconds [73], [74]. Considering the fact that bottom-up approach is in general slower than its top-down counterpart, achieving such manufacturing speed is very important. Thus, this achievement confirmed the great potential of such technological procedures.

During the described development, most of the leading industrial countries established the organisations committed to the progress of nanotechnology, where study of nanodimensional material properties in order to develop new processes and appliances, which in the end also bring economic results, remains the main research objective. Moreover, the education in this field and the awareness of the nanotechnology's impact on public health and security are becoming increasingly important [75], [76], [77], [78].

\section{Nanotechnology and nanoscience today and tomorrow}

Nowadays, nanotechnology is a part of our lives, which is reflected on many different areas. Alongside with nanoscience, it plays a key role in the development and revolutionary improvements in electronics, information technology, medicine, energetics, transport, environmental remediation and generally our everyday life. The expectations of future development are also very promising [79].

\subsection{Everyday life}

Numerous commercial products for everyday use, which are based on the use of nanomaterials are already available. Thin nanoparticle films on glasses, windows, computer screens and other surfaces make those surfaces water and dust repellent, anti-reflective, ultraviolet or infrared light-resistant, scratch-resistant or even electrically conductive [79]. Smart textiles with many nanosensors, which react to the stimuli from the environment and the human body are being developed [80], [81]. Nanoparticles are being added to the materials for tennis rackets, bicycles, helmets and car parts and are therefore making them lighter, stronger and more flexible. Nanostructures are also used in degreasers, stain removers and air purifiers. Another field of their use is personal care. Nanoparticles of titanium dioxide $\left(\mathrm{TiO}_{2}\right)$ and zinc oxide $(\mathrm{ZnO})$ have been used in sunscreens for years [79], [82].

\subsection{Medicine}

Nanotechnology is being increasingly used in modern medicine. Its contribution to the new solutions for disease prevention, diagnosis and treatment is of great importance. It is enabling the development of better diagnostic tools, which are crucial for early disease diagnoses, which increase the probability of successful treatment [79]. A promising example are the already mentioned gold nanoparticles with their unique physical properties, which can be used as probes for detection of specific nucleic acids sequences [83] and are also applicable to the most sophisticated photothermal cancer therapy methods [84]. In addition, they can serve as a tool for cancer imaging [85], [86]. Nanotechnology also has an enormous potential for treatment and diagnosis of atherosclerosis. High density lipoprotein (HDL) mimicking nanoparticles have been designed and are expected to have similar properties to native HDL, also known as "good cholesterol «, which removes cholesterol from atherosclerotic plaques [87]. Nanotechnology is also enabling the establishment of more effective drug delivery methods for the treatment 
of ophthalmological, pulmonary and cardiovascular diseases along with cancer therapy, where nanoscale delivery carriers are targeted directly to the cancer cell, improving the treatment efficiency and reducing side effects [88]. Bone and nerve tissue engineering also represent promising fields of research. It is possible to compose nanomaterials which are able to mimic the architecture of natural bone [89]. Nanoparticles have been also applied to many virus detection methods. A promising technique has recently been reported to detect severe acute respiratory syndrome coronavirus 2 (SARS-CoV-2), which causes coronavirus disease 19 (COVID-19). They are also suitable for targeted vaccine delivery to mucosal and alveolar structures [90], which could serve as an alternative to parenteral vaccine administration [91].

\subsection{Energetics}

Nanotechnology is changing the field of traditional, as well as alternative energy sources. Numerous solutions for low loss energy generation and distribution with less of a negative environmental impact are being researched [79].

Nanocatalysts are improving the efficiency of many conversion processes in petroleum processing industries [92]. Moreover, car fuel consumption can be reduced by adding metallic nanoparticles to fuel, which ensure more efficient combustion [93]. Already described CNTs have proved effective as a low-temperature adsorbents for carbon dioxide $\left(\mathrm{CO}_{2}\right)$ capture from power plant flue gas [94]. CNT fibres also have a future potential to be used in electrical wiring. By controlled assembly of CNTs, material with excellent electrical conductivity could be produced [95]. In addition, improved materials for wind turbine blades are also being developed using CNTs, which enable production of more durable and more efficient blades [96]. Nanotechnology is utilised also in the new photovoltaic solutions, where perovskite solar cells with their high efficiency and low cost represent a promising future prospect. They can also be utilised in tandem solar cells (Fig. 13), which possess a higher power conversion efficiency potential than single-junction solar cells [97]. Different principles, including the utility of colloidal quantum dots are also being developed for thermoelectric generators, which can be used in converting waste heat into electrical power [98].

\subsection{Environmental protection}

In addition to the mentioned energy efficiency improvements, nanotechnology also offers other possibilities, which can lead to better environmental protection. Advancements are being achieved in detecting and removing the contaminants from different substances [79].

Water purification is one of the most common examples where nanomaterials can be utilised, improving existing remediation technologies [100]. Another example is water desalination with a single-layer molybdenum disulphide $\left(\mathrm{MoS}_{2}\right.$ ) nanopore, which can effectively reject ions, allowing water flux that is two to five orders of magnitude greater comparing to other known nanoporous membranes [101]. Nanotechnology based techniques, using nanoscale zero-valent iron, CNTs and other nanomaterials are being developed for oil removal, which can contribute to future improvements of oil spill remediation [102]. Toxic gases in the ambient air can also be removed, exploiting adsorption properties of CNTs and gold nanoparticles [100]. CNTs can also be utilised in biosensors with fast responses and high sensitivity due to their electrical conductivity, which is highly dependent on the concentration of certain gas molecules [1]. Fig. 14 depicts a FET-based CNT sensor structure.

\subsection{Transport}

Nanotechnology offers various possibilities for improving the existing technologies for automotive industry. With its capability to preserve lighter and stronger

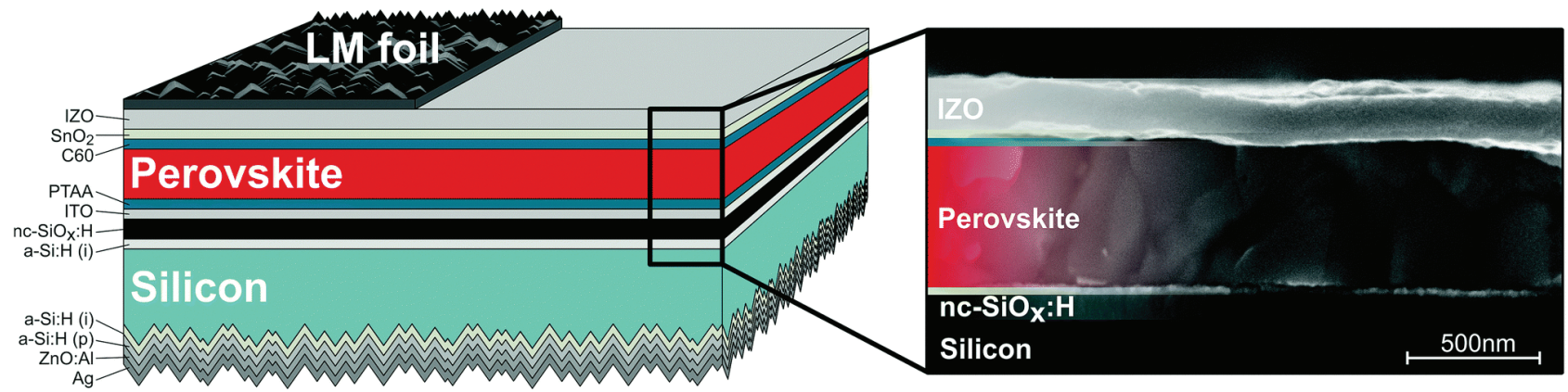

Figure 13: Structure of a perovskite-silicon tandem solar cell. Reprinted from [99]. Licensed under CC BY-NC 3.0 license. 


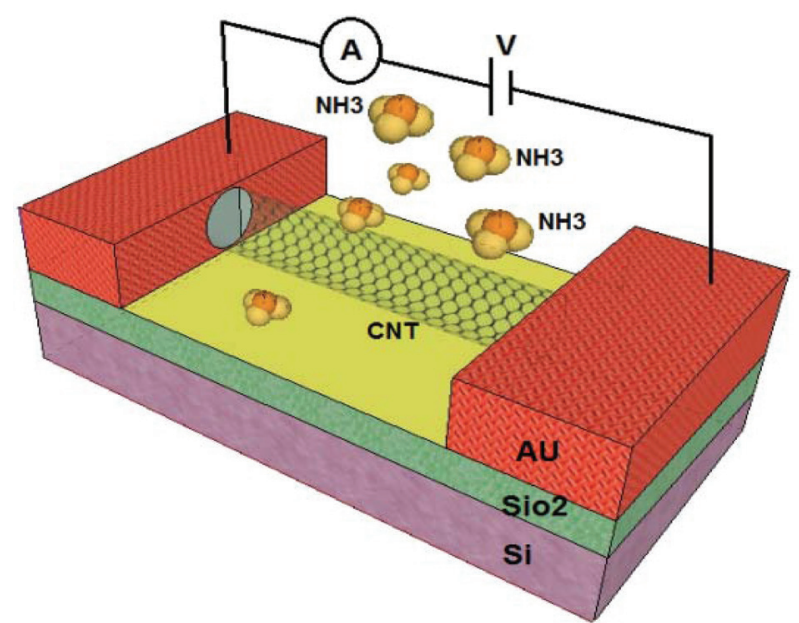

Figure 14: CNT gas sensor. Reprinted with modification (cropping) from [103]. Licensed under CC BY 3.0 license.

body parts and therefore enhance safety and fuel efficiency, it can be incorporated in various parts of the vehicle. Coating with nanoparticles can improve the durability of paint and make it more scratch-resistant. In addition, ultra-thin hydrophobic layers of aluminium oxide on the mirrors significantly reduce the light reflection. Moreover, nanoparticles of aluminium oxide can improve the tire durability when added to the rubber composite. Aluminium nanomaterials also have the potential to reduce friction of the engine cylinder walls, and therefore improve the engine efficiency [104]. Nano-composite materials are also very promising in the field of aviation. CNT reinforced polymer (CNRP) can be incorporated in airframes, as an alternative to conventional aluminium. Study of O'Donnell and Smith [105] showed, that a decrease in airframe structural mass of $10,07 \%$ on average, as a consequence of using CNRP, resulted in decreased fuel consumption of 11,2\%. Composite materials, reinforced with CNTs could also reduce icing effects [104]. Furthermore, nanotechnology also enables the progress in materials used for maritime transport. A study was made, where material with nanostructured titanium dioxide $\left(\mathrm{TiO}_{2}\right)$ polymer coating proved to have higher corrosion resistance in seawater [106].

Alongside with all abovementioned improvements and future prospects, the transport engineering is also predicted to utilize nanotechnological solutions in future [107]. Nanostructure modification of materials should enhance their performance [108]. Nanoparticles represent one of the key technologies available for self-healing asphalt pavement design [109]. Highly sensitive nanosensors could also be embedded in concrete and asphalt materials and therefore be used for the monitoring of road infrastructures [110].

\subsection{Electronics and information technology}

As already described, an astonishing progress has been made in electronics during the last fifty years. However, the miniaturisation has also brought many aforementioned issues, which do not allow further development of CMOS technology only by downscaling planar silicon MOSFETs. Consequently, new approaches are being developed by using different materials, where the special nanodimensional characteristics play a significant role. Despite the fact that silicon technology is still far from being replaced, the breakthroughs in nanotechnology clearly indicate that the development in the field of electronics is not going to stagnate soon [1].

\subsubsection{Carbon nanotubes}

As much as in other fields, CNTs also represent a promising prospect in electronics. Similar as in the silicon technology, the p-type and n-type nanotube together form an element with semiconducting properties. Likewise, a structure with the properties similar to those of heterojunction diode can be formed using a p-type semiconductor nanotube and a metal nanotube. If such a structure is placed on a silicon dioxide substrate with a gate contact, an element, similar to the junction field effect transistor (JFET) is formed. First experimental versions of CNT field effect transistors (CNTFET) were introduced in 1998. Metal contacts were placed on the layer of oxide, which was deposited on the silicon gate. Then, a CNT, which served as a channel, was grown between the metal electrodes by chemical vapour deposition (Fig. 15). Researches have shown that by increasing gate voltage, the Schottky-barrier on the metal-nanotube junctions is being decreased, thus increasing the current [1].

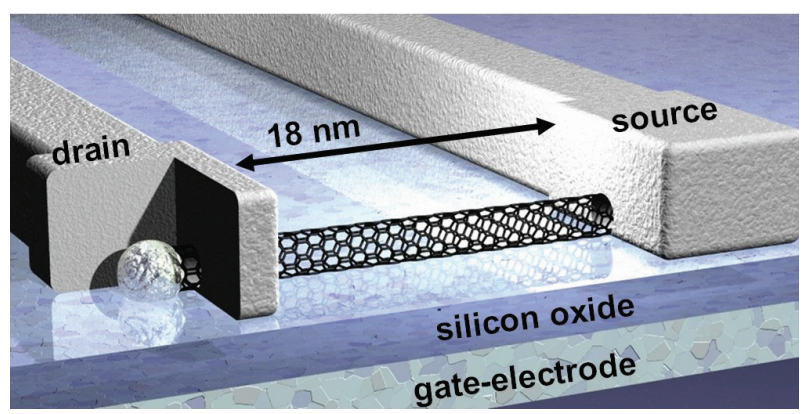

Figure 15: Structure of CNTFET with a channel length of $18 \mathrm{~nm}$, constructed by Infineon in 2004. Reprinted from [111]. Copyright 1999 - 2020 Infineon Technologies AG.

The design of CNTFET electrical circuits is quite similar to conventional technologies. The capability of creating both p-type and n-type nanotubes enables the design of CMOS-like circuits, identical to those in the silicon technology, which are known to be the most energy ef- 
ficient. Extraordinary properties of CNTs represent the main advantage of CNTFETs over conventional MOSFETs. Clock frequencies up to $1 \mathrm{THz}$ could be reached in the future due to their high carrier mobility [1]. With their energy efficiency and extremely small dimensions, those transistors represent one of the most perspective candidates for the successor of silicon-based technology. Nevertheless, the development of such transistors is facing numerous problems. Firstly, it is impossible to synthesise only semiconducting nanotubes. To achieve that, the diameter and chirality of CNTs would have to be precisely controlled. Thus, every CNT synthesis results in a certain percentage of metallic CNTs, whose conductance cannot be sufficiently modulated by the gate of CNTFET. Secondly, CNTs bundle together into random structures during wafer fabrication, which results in CNTFET failure. Thirdly, the conventional CMOS technology demands the fabrication of transistors with precisely controlled and tuneable properties, which is a severe issue by CNTFETs [112]. In 2013, Shulaker et al. in [113] demonstrated a miniature one-bit computer, made from 178 CNTFETs, whereas in 2019 they introduced a 16-bit microprocessor, comprising more than 14000 CNTFETs. During its development, they evolved new techniques of circuit design for significantly decreasing the effect of metallic CNTs. Moreover, they developed an efficient process for removing undesirable CNT bundles on the wafer, using special adhesive promoters and solvents [112]. They predict that CNTs in combination with the silicon-based technology could become a part of the integrated circuits production in few years [114].

The CNTs are also very promising in the field of data storage. Nano random access memory (NRAM) structures, whose cells comprise of hundreds of CNTs, positioned between two electrodes, are being developed. Depending on the voltage on the electrodes, nanotubes connect or disconnect from each other (Fig. 16), which reflects in changed resistance, representing a logical one or zero. One of the main advantages of NRAM is the non-volatility of CNTs, caused by molecular binding forces, which keep them connected or separated without any voltage applied. NRAM is projected to retain data for more than 300 years at $300^{\circ} \mathrm{C}$. Furthermore, by stacking the layers of memory cells on top of each other, very high data storage density could be achieved in the future [115].

CNTs can also be utilised as light sources in optoelectronics. Under certain circumstances, electrons and holes can enter the CNT simultaneously from the opposite sides. When they meet, a recombination occurs, where the electron jumps from the conduction to the valence band, releasing the energy in the form of light. Another promising future area of usage are the ultra-

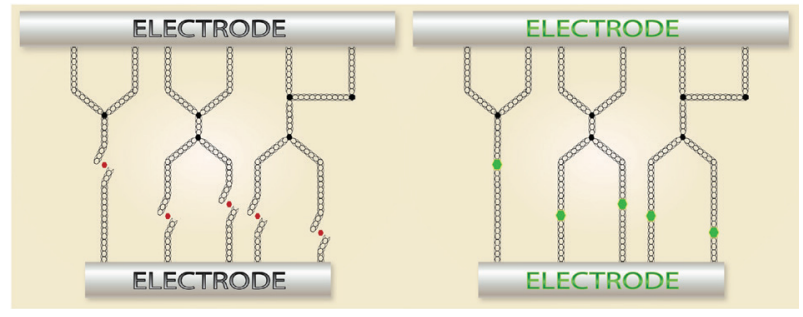

Figure 16: Working principle of NRAM. Data is stored by connecting or disconnecting CNTs between the electrodes. Reprinted with modification (cropping) from [116]. Copyright 2020 Nantero.com.

thin computer screens, which are based on the field electron emission of the CNTs and are expected to be very energy efficient with better brightness and longer life span [1].

\subsubsection{Quantum dots}

Quantum dots also possess many potential applications in electronics. Besides of those using the light emission of electron, which returns to the ground state, there are also other possibilities for their utilization. Quantum dot is a part of single-electron transistor. That is a structure, where the electrons are tunnelling between either source or drain and the quantum dot in between. The amount of energy needed for the tunnelling to take place is tuned by the third electrode - the gate, which is capacitively coupled to the quantum dot island (Fig. 17) [117].

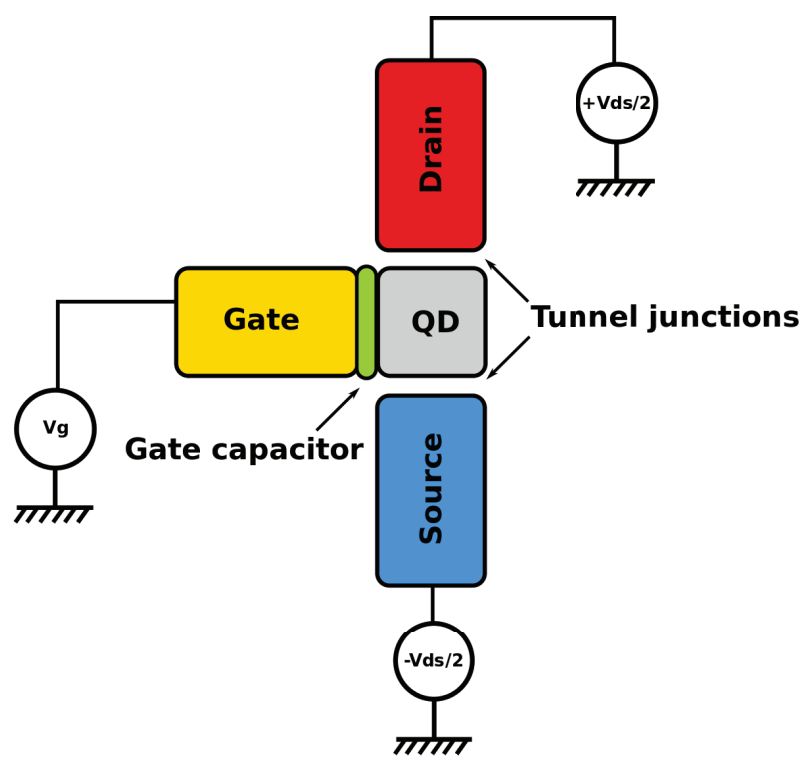

Figure 17: Schematic visualisation of a single-electron transistor. Reprinted from [118]. Visualisation is in the public domain.

Tunnelling of the electrons, which results in electrical current, is due to the Coulomb blockade possible only when appropriate combination of voltages is applied 
to the gate terminal and between drain and source electrodes (Fig. 18). Thus, the switching operation of the transistor is enabled at very low power consumption, which represents a potential for the future of logical circuits. Coulomb blockade can be observed only at small enough dimensions, which result in small capacitances between the quantum dot and the source or drain electrode. In this case, when the potential difference between for example the source and quantum dot is too small, the tunnelling is not possible due to negative change in energy, stored in electric field between the electrodes, which would occur by the transfer of an electron. However, this is valid only at temperature of $0 \mathrm{~K}$. At higher temperatures, the Coulomb blockade is observable when the mentioned change in energy is larger than the thermal energy. Therefore, at room temperature, a quantum dot must be in size of few nanometres at most [1].

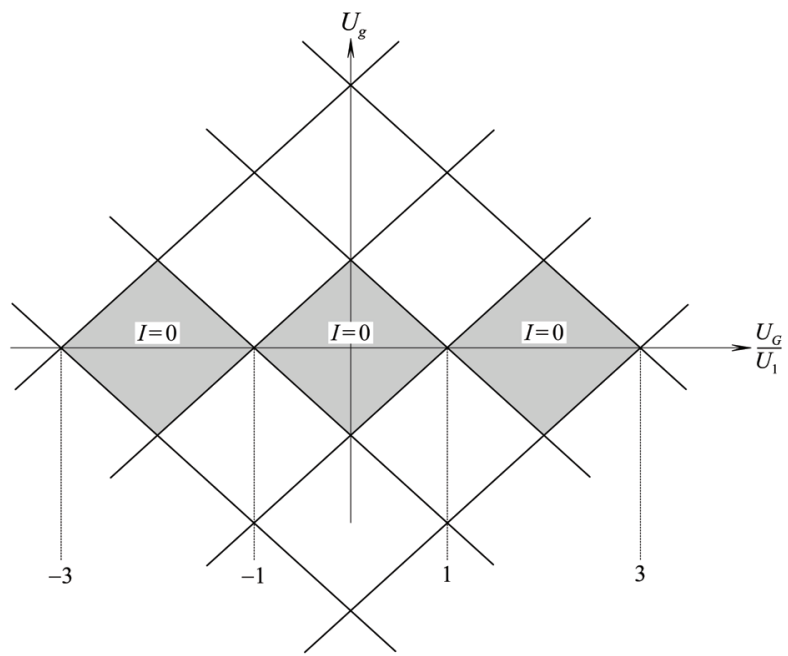

Figure 18: Stability diagram of single electron transistor. Shadowed areas depict the combinations of voltages, where tunnelling is not possible. $U_{g}$ represents drain-to-source voltage, whereas $U_{G}$ represents gate voltage. $\mathrm{U}_{1}$ equals to $\frac{q}{2 C_{G}}$, where $q$ denotes elementary charge and $C_{G}$ is the capacitance between gate electrode and quantum dot. When $U_{G}$ equals to odd multiples of $U_{1}$, the Coulomb blockade does not exist [1].

Apart from the challenges, associated with manufacturing the quantum dots in so small dimensions, the effect of random background charge also represents a problem. Impurities with trapped charge in the insulating oxide can lead to logic errors in the single-electron logic circuits or their unreliable operation. What is more, the transfer characteristics of single-electron transistor have more peaks and thus more voltages where tunnelling can occur. Consequently, the potential single-electron logic circuits are going to be sensitive to noise and voltage drift [1]. However, the features of single-electron transistors make them usable in su- persensitive electrometers, infrared radiation detectors and also memory devices [119].

\subsubsection{Spintronics}

Another field, which offers promising possibilities for advancement, especially in data storage technologies, is spintronics. That is a fairly new discipline, which deals with manipulation of the electron's spin in order to code, store, transfer and process the information. By using the spin of electron instead of its charge, many improvements could be made in the field of electronics [1]. One of the most promising applications of the principles of spintronics is magnetoresistive random access memory (MRAM), based on the magnetoresistance effect, where the resistance of material, in this case a ferromagnetic, is being changed in the presence of magnetic field [120]. The ability of movement of electrons in a ferromagnetic material depends on their spin orientation in relation to the material magnetisation. Electrons with spin orientation parallel to the magnetisation move unlimitedly, in contrary to the electrons with antiparallel spin orientation, who thus feel higher resistance [1]. Utilizing this property, a spin valve was designed, which served as a basis for the first storage element in MRAM. It consisted of two ferromagnetic layers with a non-magnetic conductive layer in between. One of the ferromagnetic layers had an antiferromagnetic layer in its proximity, which made it fairly insensitive to the applied magnetic field. This ferromagnetic layer was therefore called "pinned" or "fixed" layer, while the other one was "free", because its magnetisation could be changed. Therefore, a parallel or antiparallel magnetisation of layers could be achieved [120]. By parallel magnetisation, electrons with particular spin orientation felt low resistance in both layers, whereas the other ones felt high resistance
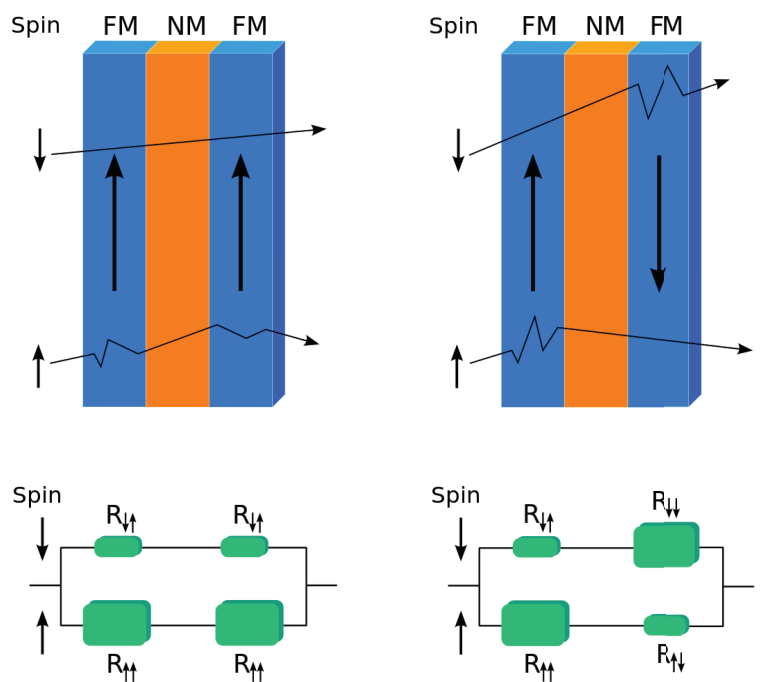

Figure 19: Resistive model of spin valve. Reprinted from [121]. Licensed under CC BY-SA 3.0 license. 
in both layers. By antiparallel magnetisation, electrons of each spin orientation felt high resistance in one of the layers. With the current of both groups of electrons being independent of each other, the equivalent resistance was higher by antiparallel magnetisation, as depicted in Fig. 19. Hence, data could be stored by affecting the free layer magnetisation [1].

A big breakthrough was made in the late 1980s, when the spin valve based structures were discovered, whose resistance changed for up to $80 \%$ due to the applied magnetic field. This was called giant magnetoresistance (GMR) [1]. However, the practical GMR, which could be used in MRAM has remained too low to produce a sufficient voltage difference between the high and low resistance states [120]. As an improvement, the magnetic tunnel junction (MTJ) structures, using tunnel magnetoresistance (TMR), were developed. TMR structures are similar to GMR, except they have a very thin insulator film between the ferromagnetic layers instead of a non-magnetic layer. Therefore, the electrons can tunnel through the insulating film, where the probability of tunnelling is higher by parallel magnetisation, resulting in lower resistance. The values of the resistance change based on TMR have already achieved $100-200 \%$ in MRAM devices, which produces a significant voltage difference between logic states.

The basic principle of writing in MRAM is based on applying a magnetic field to appropriate cell, which switches the magnetisation in free layer. MRAM architecture consists of word and bit lines, which are orthogonal to each other (Fig. 20). The magnetic field is strong enough to alter the magnetisation in a data cell only when the current flows through both corresponding lines, which allows the addressing of each cell separately $[1],[120]$.

However, at smaller cell dimensions, higher switching field and consequently higher current is necessary, which limits the scalability of field-assisted MRAM to about $90 \mathrm{~nm}$. As a solution, spin transfer torque (STT) MRAM was introduced, where the switching of magnetisation was induced by a current, flowing through the device (Fig. 21). If the magnetisation needs to be switched from antiparallel to parallel, the electrons are sent from a pinned layer to free layer. In the pinned layer, the electrons with a spin in the opposite direction to magnetisation get scattered and the others pass to the free layer. There, the spin angular momentum exerts a torque on the magnetisation, resulting in its switching to parallel direction. In order to achieve switching from parallel to antiparallel magnetisation, the current must flow in the opposite direction. In this case, the electrons flow from the free to pinned layer. The electrons with spin orientation antiparallel to magnetisation get scat- tered back to the free layer, where they cause a switch to antiparallel magnetisation. STT MRAM allows scaling to smaller dimensions than MRAM with magnetic fieldbased writing [120].

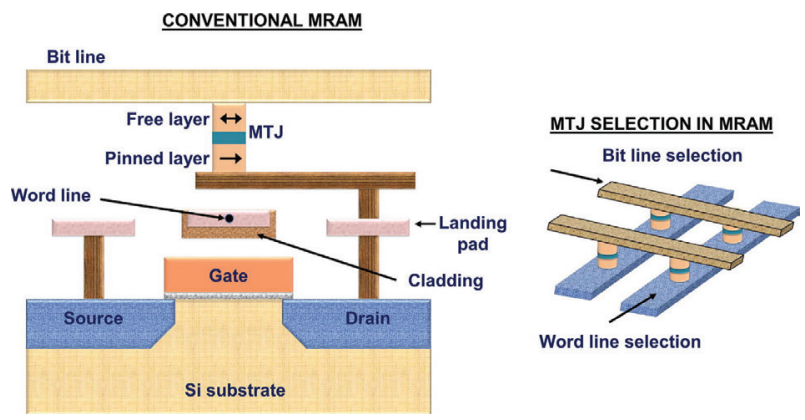

Figure 20: Schematic representation of conventional MRAM architecture, where magnetisation of free layer is set by applying sufficient magnetic field to the cell. To achieve that, current must flow through both corresponding word line and bit line. Reprinted from [120]. Licensed under CC BY-NC-ND 4.0 license.

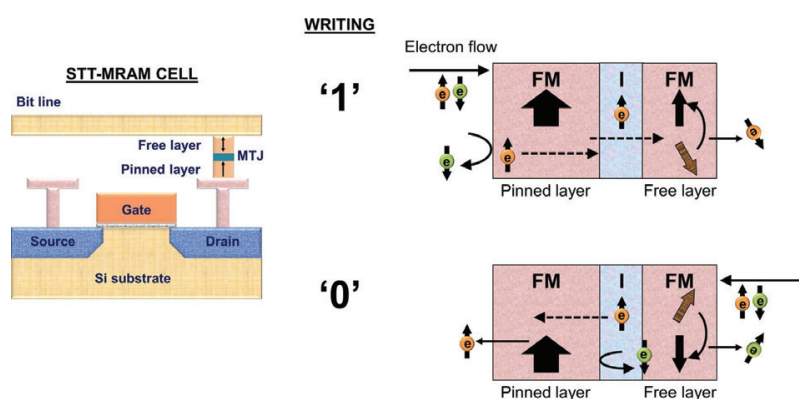

Figure 21: STT MRAM cell and its writing principle. Reprinted from [120]. Licensed under CC BY-NC-ND 4.0 license.

One of the main advantages of MRAM in general is its non-volatility, which is achieved by retentivity of ferromagnetic materials. Nevertheless, to achieve long lasting data retention, sufficient thermal stability of MTJ must be provided. By the in-plane MTJs, where the magnetisation of ferromagnetic layers is in the film plane (Fig. 22), this is hardly achievable for the cells with diameter less than $60 \mathrm{~nm}$. Therefore, the MTJs with perpendicular magnetisation (pMTJ) are being increasingly researched [120]. Moreover, the critical switching current density, at which the magnetisation direction in free layer is rotated by the STT effect, can be considerably reduced, using PMTJ [122]. Thus, MRAMs with perpendicular magnetisation are considered to replace in-plane ones in the near future [120].

With all the mentioned attributes, STT MRAM is considered as a perfect candidate for future memory applications. However, the issue of a relatively high switching 
current and consequently high energy consumption will have to be solved in order to launch MRAM successfully into the computer memory market [123].

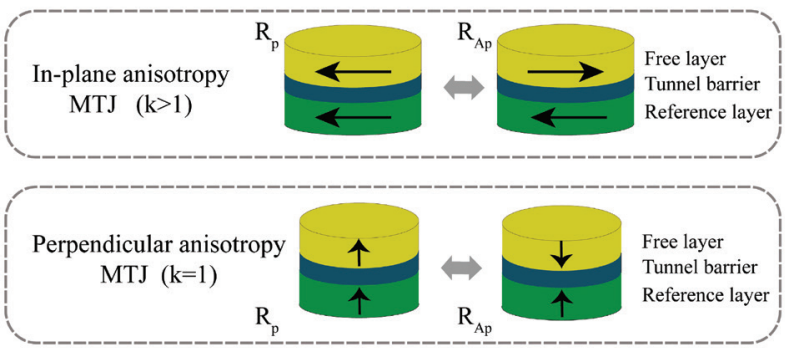

Figure 22: MTJ with in-plane and perpendicular magnetisation, where $k$ represents width-to-length ratio of MTJ. By in-plane magnetisation, MTJs must have elliptical shape in order to prevent the formation of vortex magnetisation in the films, which is another downside of in-plane MTJs regarding scalability [120]. Reprinted with modification (cropping) from [124]. Licensed under CC BY 4.0 license.

\subsubsection{Memristor}

When talking about the potential future data storage solutions, it is appropriate to mention memristor. This is an element, which was theoretically described in the 1970s by Leon Chua and in its essence represents a relation between the electric charge and magnetic flux. Chua came to a conclusion that memristor therefore represents the fourth fundamental component of electrical circuits, alongside with the capacitor, resistor and inductor. The main property of memristor is that its resistance is being changed by the current, which flows through it. It is very important that this resistance retains its value after the current is shut down, which means that memristor can be used as a non-volatile memory device, whose high or low resistance represents one bit of information [1].

Physical realisation of memristor had not taken place until 2008, when the company Hewlett Packard (HP) introduced an element with allegedly memristive properties. It was made of a thin layer of titanium dioxide $\left(\mathrm{TiO}_{2}\right)$, embedded between two platinum (Pt) electrodes. A part of $\mathrm{TiO}_{2}$ layer was oxygen deficient and therefore acted as an electrically conductive doped semiconductor due to the oxygen vacancies, which acted as dopants. The other part was not conductive. With external voltage applied, positively charged vacancies moved in the direction of electric field. When the vacancies drifted towards the opposite Pt electrode, the conductive channels were created at some point, switching the device on. When they drifted away, the channels were dispersed and the electronic barrier was recovered, switching the device off [125], [1]. Described memristive effects are highly dependent on the device's dimensions. They are remarkably more significant at the nanometre scale, which explains the fact that memristor was not physically realised before the immense progress in the field of nanotechnology [1]. The discussions are common, whether the mentioned realisation actually is a memristor, as described by Leon Chua, or it just exhibits some similar characteristics. Despite the fact that both the justification of memristor as the fourth fundamental electrical component and the actual realisation of theoretically proposed memristive properties are on shaky grounds, the memristor certainly represents a big promise in data storage, logic circuits and neural networks [1].

Several different types of memristive devices have been proposed so far, for example redox-based, ferroelectric, multiferroic and spin-based memristors [126]. In 2017, Samardžić et al. presented a multiferroic multilayer memristor, composed of $\mathrm{BaTiO}_{3} / \mathrm{NiFe}_{2} \mathrm{O}_{4} / \mathrm{BaTiO}$ thin films, deposited on platinised silicon wafers by spincoating. Bottom electrode was therefore platinum, whereas the upper one was golden. The investigated memristor proved to have typical current-voltage characteristics in the form of pinched hysteresis loop, which was symmetric and repeatable for the voltage amplitudes of $\pm 10 \mathrm{~V}$. Two conducting mechanisms were identified. Fowler-Nordheim tunnelling for the applied voltages above $5 \mathrm{~V}$ and thermionic emission for lower voltages and higher temperatures [126]. In 2019, Lu et al. demonstrated purely electronic memristors, fabricated from amorphous silicon, doped with oxygen or nitrogen and embedded between metal electrodes. Such memristive devices could be easily integrated into conventional silicon technology, which is one of their main advantages [127]. Memristors have also found their way to biological computing. In 2020, Fu et al. presented a diffusive memristor, made of protein nanowires of the bacterium Geobacter sulfurreducens, functioning at low, biological voltages (40-100 mV) [128]. Diffusive memristors spontaneously relax back to non-conductive state, after the bias voltage for switching to conductive state is removed [129]. Hence, they enable emulations in short and long-term memory synapses, artificial neurons and neural networks [128], [129]. The artificial neuron, constructed with diffusive protein-nanowire memristors achieved similar temporal integration as biological neurons [128].

Various ways of memristors' utilisation have been introduced in the past few years. Memristor crossbar arrays with potential applications in non-volatile memory, logic circuits and neuromorphic computing systems have been proposed and realised [130]. Two nanometre feature size memristor crossbar arrays with a single-layer density comparable to information density achieved with state-of-the-art flash memory devices were re- 
alised in 2018. Such structures represent a promising solution for power efficient information storage and processing [131]. Multi-bit memristive devices, which possess more than two distinctive resistance states, have also been proposed. In 2015, a microscale $\mathrm{TiO}_{2}$ based memristor with silver and indium tin oxide electrodes was made and proved to have quantised conductance steps that were integer multiples of elementary conductance [132]. Two years later, memory cells with up to 6.5 bits information storage and long-lasting data retention have been developed [133]. Memristors with large number of conducting states could be very useful in artificial neural networks. Several researches have been made in this field. Graphene based nonvolatile memristive synapses were introduced recently, with more than 16 arbitrarily programmable conductance states [134].

\subsection{Funding of nanotechnology}

Nanotechnology and nanoscience are becoming increasingly important driving forces for the modern world's development. It is estimated that governments worldwide invested over \$67 billion in nanotechnology research between years 2000 and 2015. They also represent a significant part of European Union's (EU) research funding programmes. Under the Seventh Framework Programme (FP7), €2.56 billion was devoted for the projects in the fields of nanotechnology and nanoscience between years 2007 and 2011, mostly coming through the "Nanosciences, Nanotechnologies, Materials \& new Production Technologies (NMP)" scheme [135]. Between 2014 and September of 2020, $€ 56.4$ billion was earmarked for the projects of Horizon 2020, EU research and innovation funding programme [136]. Under that programme, an estimated total budget of $€ 1.77$ billion was devoted only for the programme part "Nanotechnologies, Advanced Materials, Biotechnology and Advanced Manufacturing and Processing" between years 2018 and 2020 [137]. There are also other initiatives in the field of nanotechnology, funded under the same programme. One of them is Graphene Flagship with planned budget of $€ 1$ billion, which was initiated in 2013 and is still in progress [138]. The same budget is predicted for the Quantum Technologies Flagship initiative, which started in 2018 and supports quantum technologies research in Europe [139]. The funding of these initiatives will be continued by the programme Horizon Europe, which will span from 2021 to 2027 and have a budget of around $€ 100$ billion [140]. It is therefore reasonable to expect that the research in the fields of nanoscience and nanotechnologies is going to be increasingly funded by the EU in future.

\subsection{A look to the future}

With such financial support, we can expect an immense progress in these fields in next years. New solutions will have to be found in order to continue the development of the electronics' industry, according to the Moore's law. CNTFETs certainly have a potential to succeed the silicon based technology. However, the complete transition to CNTFETs is not likely to happen in the near future, due to the many manufacturing difficulties. We will more probably face gradual changes, in the form of incorporating CNTs as parts of the silicon based circuits, which could already happen in the present decade [114]. Nevertheless, the silicon transistors with nanosheets are yet to come into mass production in the next technology nodes, which implies that silicon will not be replaced very soon. In addition, it is more likely that it will be succeeded by more efficient, for example III-V semiconductors, before the CNTs play a significant role [27]. Most probably, the future electronic circuits will firstly be designed using combinations of mentioned materials.

Besides new materials and transistor types, different design and manufacturing principles could also contribute to the progress in the field of electronics. An interesting example is wafer-scale processing, where the whole silicon wafer is used for production of a single chip. This approach can be useful in designing highperformance computers, which execute computationally demanding tasks, like training deep artificial neural networks. A very large number of processor cores and memory units can therefore be integrated on a single chip, which significantly increases communication bandwidth and decreases processing times [141]. In 2019, a computer systems company Cerebras introduced a chip, measuring $46.255 \mathrm{~mm}^{2}$, with more than 1.2 trillion transistors and 400,000 cores, using TSMC's $16 \mathrm{~nm}$ fabrication technology [142], [143]. In 2020, they announced a second generation of the chip, which comprised 850,000 artificial intelligence optimised cores and 2.6 trillion transistors, using TSMC's $7 \mathrm{~nm}$ technology [144].

Another field, which will importantly benefit from the progress of the nanotechnology is medicine. Promising methods are being developed for early diagnosing of different diseases, including certain types of cancer and diabetes, by detecting biomarkers in human breath [135], [145]. Furthermore, graphene quantum dots have shown the potential to treat the Parkinson's as well as Alzheimer's disease, which could change the life of millions of people in the future [146], [147], [148]. Targeted drug delivery with the use of nanoparticles is also a promising field, which will provide less invasive treatment, especially for cancer patients [135]. One of 
the most perspective areas of nanotechnology in general, the self-assembly of structures, will also affect the field of medicine, in terms of self-repair mechanisms. Methods are being developed, where the nanostructured scaffolds are used to direct the growth of cardiac, bone and skin tissues [135].

Self-assembly will certainly represent a future revolution in many areas of technology. Assembling of molecules in particular structure without external intervention is an essential tool, which makes the bottom-up fabrication possible. It will enable the development of CNT based electronic devices and also be increasingly used in energy and environmental remediation applications. Low cost and highly efficient perovskite solar cells with self-assembled monolayers are already being developed, contributing to the progress of this perspective solar technology [149].

\section{Conclusions}

Considering all the above, it is clear that nanotechnology and nanoscience are going to affect our lives in the future. In this review paper, only positive effects of this field are presented. However, numerous questions are being set about the negative impacts of nanotechnology on health and also about its ethics. Although some hesitations may really be unjustified and only appear due to the fear of the unknown, which is a part of human nature, these questions will have to be addressed and resolved before the wider use. Nevertheless, despite the fact that this field of science is relatively new and the mankind's coexistence with it is still in its beginnings, it definitely has a bright future, possessing a great potential to improve our and our descendants lives.

\section{Conflict of interest}

The authors declare no conflict of interest.

\section{References}

1. F. Smole, Nanoelektronika, 1. Ljubljana: Založba FE in FRI, 2014.

2. S. Bayda, M. Adeel, T. Tuccinardi, M. Cordani, and F. Rizzolio, "The history of nanoscience and nanotechnology: From chemical-physical applications to nanomedicine," Molecules, vol. 25, no. 1. MDPI AG, p. 112, 2019, https://doi.org/10.3390/molecules25010112.
3. "What's So Special about the Nanoscale? | nano. gov." https://www.nano.gov/nanotech-101/special (accessed Nov. 29, 2020).

4. "Nano Gold | 4cast web-tool | PHORNANO Holding GmbH." https://www.phornano.com/4ngold (accessed Nov. 29, 2020).

5. G. Binnig and H. Rohrer, "Scanning tunneling microscopy from birth to adolescence," Rev. Mod. Phys., vol. 59, no. 3, pp. 615-625, 1987, https://doi.org/10.1103/RevModPhys.59.615.

6. "The Nobel Prize in Physics 1986." https://www. nobelprize.org/prizes/physics/1986/summary/ (accessed Nov. 29, 2020).

7. "The Nobel Prize in Physics 1956 - NobelPrize. org." https://www.nobelprize.org/prizes/physics/1956/summary/ (accessed Nov. 29, 2020).

8. "Nokia Bell-Labs Timeline." https://www.bell-labs. com/timeline/\#/1940/1/open/ (accessed Dec. 22, 2020).

9. M. Riordan, "The lost history of the transistor," IEEE Spectr., vol. 41, no. 5, pp. 44-49, 2003, https://doi.org/10.1109/MSPEC.2004.1296014.

10. J. S. C. Kilby, "Turning potential into realities: The invention of the integrated circuit (Nobel lecture)," ChemPhysChem, vol. 2, no. 8-9. Wiley-VCH Verlag, pp. 482-489, Aug. 17, 2001, https://doi.org/10.1002/1439-7641(20010917)2:8/9<482:aid-cphc482>3.0.c0;2-y.

11. R. K. Basset, To the Digital Age: Research Labs, Startup Companies and the Rise of MOS Technology (Johns Hopkins Studies in the History of Technology). Baltimore: Johns Hopkins University Press, 2002.

12. S. L. Moskowitz, Advanced Materials Innovation: Managing Global Technology in the 21st century. John Wiley \& Sons, 2016.

13. "File:Grown-junction NPN transistor type ST2010. png - Wikimedia Commons." https://commons. wikimedia.org/wiki/File:Grown-junction_NPN_ transistor_type_ST2010.png (accessed Feb. 27, 2021).

14. "Nokia Bell-Labs Timeline." https://www.bell-labs. com/timeline/\#/1950/1/open/ (accessed Feb. 27, 2021).

15. “Jack Kilby's Integrated Circuit | National Museum of American History." https://americanhistory. si.edu/collections/search/object/nmah_689592 (accessed Feb. 27, 2021).

16. "File:Fairchild uA741 opamp 6920.jpg - Wikimedia Commons." https://commons.wikimedia.org/ wiki/File:Fairchild_uA741_opamp_6920.jpg (accessed Feb. 27, 2021).

17. "Intel A80386DX-20." https://www.cpu-world. com/CPUs/80386/Intel-A80386DX-20.html (accessed Feb. 27, 2021).

18. "File:Intel A80386DX-20 CPU Die Image.jpg - Wikimedia Commons." https://commons.wikimedia. 
org/wiki/File:Intel_A80386DX-20_CPU_Die_Image.jpg (accessed Feb. 27, 2021).

19. G. E. Moore, "Cramming more components onto integrated circuits. In: Electronics," Electronics, 1965, [Online]. Available: https://www.cs.csub. edu/ melissa/cs350-f15/notes/Doc/gordon_ moore_1965_article.pdf.

20. G. E. Moore, "Progress in digital integrated electronics," Electron devices meeting. 1975, [Online]. Available: http://ai.eecs.umich.edu/people/conway/VLSI/BackgroundContext/SMErpt/AppB.pdf.

21. B. Knehr, J. Lewis, and C. Morse, "Developmental History of main-line Intel CPUs," 2002. [Online]. Available: https://users.cs.jmu.edu/abzugcx/Public/Student-Produced-Term-Projects/ComputerOrganization-2002-SPRING/Intel-CPUs-by-ClintMorse-Jeff-Lewis-Brian-Knehr-2002-SPR.doc.

22. "International Technology Roadmap for Semiconductors - ITRS 2.0 Home Page." http://www.itrs2. net/ (accessed Nov. 29, 2020).

23. "The International Roadmap for Devices, International Roadmap for Devices and Systems; 2017 Edition; More Moore," 2018. Accessed: Nov. 29, 2020. [Online]. Available: https://irds.ieee.org/images/files/pdf/2017/2017IRDS_MM.pdf.

24. "The National Technology Roadmap for Semiconductors," 1994. Accessed: Nov. 29, 2020. [Online]. Available: http://www.rennes.supelec.fr/ren/perso/gtourneu/enseignement/roadmap94.pdf.

25. H. S. P. Wong et al., "A Density Metric for Semiconductor Technology [Point of View]," Proceedings of the IEEE, vol. 108, no. 4. Institute of Electrical and Electronics Engineers Inc., pp. 478-482, Apr. 01, 2020,

https://doi.org/10.1109/JPROC.2020.2981715.

26. "Process Technology History - Intel - WikiChip." https://en.wikichip.org/wiki/intel/process (accessed Nov. 29, 2020).

27. P. Ye, T. Ernst, and M. V. Khare, "The last silicon transistor: Nanosheet devices could be the final evolutionary step for Moore's Law," IEEE Spectr., vol. 56, no. 8, pp. 30-35, Aug. 2019, https://doi.org/10.1109/MSPEC.2019.8784120.

28. "Samsung Electronics on Track for 10nm FinFET Process Technology Production Ramp-up - Samsung Global Newsroom." https://news.samsung. com/global/samsung-electronics-on-track-for$10 \mathrm{~nm}$-finfet-process-technology-productionramp-up (accessed Dec. 22, 2020).

29. "File: Moore's Law Transistor Count 1971-2018. png - Wikimedia Commons." https://commons. wikimedia.org/wiki/File:Moore\%27s_Law_Transistor_Count_1971-2018.png (accessed Dec. 27, 2020).

30. Y. Ding et al., "A Device Design for $5 \mathrm{~nm}$ Logic FinFET Technology," J. Microelectron. Manuf., vol. 3, no. 1 , pp. $1-8,2019$,

https://doi.org/10.33079/jomm.20030105.

31. A. Artashyan, "Samsung Electronics Has Already Begun Mass Production Of 5nm Chips." https:// www.gizchina.com/2020/07/30/samsung-electronics-has-already-begun-mass-production-of5nm-chips/ (accessed Nov. 29, 2020).

32. I. Cutress, "Samsung Announces 3nm GAA MBCFET PDK, Version 0.1." https://www.anandtech. com/show/14333/samsung-announces-3nmgaa-mbcfet-pdk-version-01 (accessed Nov. 29, 2020).

33. "Samsung Electronics' Leadership in Advanced Foundry Technology Showcased with Latest Silicon Innovations and Ecosystem Platform - Samsung Global Newsroom." https://news.samsung. com/global/samsung-electronics-leadership-inadvanced-foundry-technology-showcased-withlatest-silicon-innovations-and-ecosystem-platform (accessed Dec. 22, 2020).

34. "Q2 2019 Taiwan Semiconductor Manufacturing Co Ltd EarningsCall (Edited transcript)." Thomson Reuters, Jul. , Accessed: Nov. 29, 2020. [Online]. Available: https://www.tsmc.com/uploadfile/ir/ quarterly/2019/2NQYt/E/TSMC 2Q19 transcript. pdf.

35. N. Mojarad, J. Gobrecht, and Y. Ekinci, "Beyond EUV lithography: A comparative study of efficient photoresists' performance," Sci. Rep., vol. 5, no. 1, pp. 1-7, Mar. 2015, https://doi.org/10.1038/srep09235.

36. A. A. Long, The Cambridge Companion to Early Greek Philosophy (Cambridge Companions to Philosophy). Cambridge University Press, 1999.

37. B. Rogers, J. Adams, and S. Pennathur, Nanotechnology: Understanding Small Systems, Third Edition, $3^{\text {rd }}$ ed. CRC Press, 2015.

38. "2.1: A History of Atomic Theory - Chemistry LibreTexts." https://chem.libretexts.org/Courses/ Oregon_Institute_of_Technology/OIT\%3A_ CHE_201_-_General_Chemistry_I_(Anthony_ and_Clark)/Unit_2\%3A_The_Structure_of_the_ Atom/2.1\%3A_A_History_of_Atomic_Theory (accessed Feb. 23, 2021).

39. "The History of the Atom - Theories and Models - Compound Interest." https://www.compoundchem.com/2016/10/13/atomicmodels/ (accessed Feb. 23, 2021).

40. "File:Plum pudding model.svg - Wikimedia Commons." https://commons.wikimedia.org/wiki/ File:Plum_pudding_model.svg (accessed Feb. 25, 2021).

41. "File:Rutherford atom.svg - Wikimedia Commons." https://commons.wikimedia.org/wiki/ File:Rutherford_atom.svg (accessed Feb. 26, 2021). 
42. "File:Bohr atom model.png - Wikimedia Commons." https://commons.wikimedia.org/wiki/ File:Bohr_atom_model.png (accessed Feb. 26, 2021).

43. "Atom Model Schrödinger - Free image on Pixabay." https://pixabay.com/illustrations/atommodel-schrödinger-atomic-5000565/ (accessed Feb. 26, 2021).

44. "Atom - Bohr's shell model | Britannica." https:// www.britannica.com/science/atom/Bohrs-shellmodel (accessed Feb. 24, 2021).

45. T. W. Hansch, A. L. Schawlow, and G. W. Series, "The Spectrum of Atomic Hydrogen," Sci. Am., vol. 240, no. 3, pp. 94-111, 1979, Accessed: Mar. 29, 2021. [Online]. Available: https://www.jstor.org/ stable/24965154.

46. "Schrodinger equation | Explanation \& Facts | Britannica." https://www.britannica.com/science/ Schrodinger-equation (accessed Feb. 25, 2021).

47. "Wave function | Definition \& Facts | Britannica." https://www.britannica.com/science/wave-function (accessed Feb. 25, 2021).

48. "The quantum mechanical model of the atom (article) | Khan Academy." https://www.khanacademy.org/science/physics/quantum-physics/ quantum-numbers-and-orbitals/a/the-quantummechanical-model-of-the-atom (accessed Feb. 25, 2021).

49. "Atom - The laws of quantum mechanics | Britannica." https://www.britannica.com/science/atom/ The-laws-of-quantum-mechanics (accessed Feb. $25,2021)$.

50. "Development of the Atomic Theory." http://www. abcte.org/files/previews/chemistry/s1_p6.html (accessed Feb. 25, 2021).

51. "Frederick Soddy - Facts - NobelPrize.org." https:// www.nobelprize.org/prizes/chemistry/1921/soddy/facts/ (accessed Feb. 25, 2021).

52. "Donor spin qubit in silicon | Fundamental Quantum Technologies Laboratory." https://www.fqt. unsw.edu.au/research/donor-spin-qubit-in-silicon (accessed Feb. 25, 2021).

53. J. J. Pla et al., "A single-atom electron spin qubit in silicon," Nature, vol. 489, no. 7417, pp. 541-544, Sep. 2012, https://doi.org/10.1038/nature11449.

54. J. J. Pla et al., "High-fidelity readout and control of a nuclear spin qubit in silicon," Nature, vol. 496, no. 7445, pp. 334-338, Apr. 2013, https://doi.org/10.1038/nature12011.

55. N. Taniguchi, "On the Basic concept of Nanotechnology," Proceeding ICPE, 1974.

56. G. Binnig, C. F. Quate, and C. Gerber, "Atomic force microscope," Phys. Rev. Lett., vol. 56, no. 9, pp. 930 933, Mar. 1986, https://doi.org/10.1103/PhysRevLett.56.930.
57. D. M. Eigler and E. K. Schweizer, "Positioning single atoms with a scanning tunnelling microscope," Nature, vol. 344, no. 6266, pp. 524-526, Apr. 1990, https://doi.org/10.1038/344524a0.

58. H. W. Kroto, J. R. Heath, S. C. O'Brien, R. F. Curl, and R. E. Smalley, "C60: Buckminsterfullerene," Nature, vol. 318, pp. 162-163, 1985, https://doi.org/10.1038/318162a0.

59. S. lijima, "Helical microtubules of graphitic carbon," Nature, vol. 354, pp. 56-58, 1991, https://doi.org/10.1038/354056a0.

60. "Carbon Nanotube stock illustration. Illustration of colour - 43175001." https://www.dreamstime. com/stock-illustration-carbon-nanotube-illustration-nanotechnology-scene-computer-artworkimage43175001 (accessed Dec. 22, 2020).

61. A. I. Ekimov, A. L. Efros, and A. A. Onushchenko, "Quantum size effect in semiconductor microcrystals," Solid State Commun., vol. 56, no. 11, pp. 921-924, 1985,

https://doi.org/10.1016/S0038-1098(85)80025-9.

62. S. Kailasa, K.-H. Cheng, and H.-F.Wu, "Semiconductor Nanomaterials-Based Fluorescence Spectroscopic and Matrix-Assisted Laser Desorption/lonization (MALDI) Mass Spectrometric Approaches to Proteome Analysis," Materials (Basel)., vol. 6, no. 12, pp. 5763-5795, Dec. 2013, https://doi.org/10.3390/ma6125763.

63. C. Livache et al., "A colloidal quantum dot infrared photodetector and its use for intraband detection," Nat. Commun., vol. 10, 2019, https://doi.org/10.1038/s41467-019-10170-8.

64. Z. Liu et al., "Micro-light-emitting diodes with quantum dots in display technology," Light Sci. Appl., vol. 9, 2020, https://doi.org/10.1038/s41377-020-0268-1.

65. A. J. Nozik, "Quantum dot solar cells," in Physica E: Low-Dimensional Systems and Nanostructures, Apr. 2002, vol. 14, no. 1-2, pp. 115-120, https://doi.org/10.1016/S1386-9477(02)00374-0.

66. C. T. Kresge, J. C. Vartuli, W. J. Roth, and M. E. Leonowicz, "The discovery of ExxonMobil's M41S family of mesoporous molecular sieves," in Studies in Surface Science and Catalysis, Jan. 2004, vol. 148 , pp. 53-72, https://doi.org/10.1016/s0167-2991(04)80193-9.

67. "Nanotechnology Timeline | nano.gov." https:// www.nano.gov/timeline (accessed Nov. 29, 2020).

68. H. Lee and W. Ho, "Structural determination by single-molecule vibrational spectroscopy and microscopy: Contrast between copper and iron carbonyls," Phys. Rev. B - Condens. Matter Mater. Phys., vol. 61, no. 24, pp. R16347-R16350, Jun. 2000, https://doi.org/10.1103/PhysRevB.61.R16347.

69. R. D. Piner, J. Zhu, F. Xu, S. Hong, and C. A. Mirkin, "'Dip-pen' nanolithography," Science (80-. )., vol. 
283, no. 5402, pp. 661-663, Jan. 1999,

https://doi.org/10.1126/science.283.5402.661.

70. L. R. Hirsch, J. B. Jackson, A. Lee, N. J. Halas, and J. L. West, "A whole blood immunoassay using gold nanoshells," Anal. Chem., vol. 75, no. 10, pp. 23772381, May 2003, https://doi.org/10.1021/ac0262210.

71. R. D. Barish, P. W. K. Rothemund, and E. Winfree, "Two computational primitives for algorithmic self-assembly: Copying and counting," Nano Lett., vol. 5, no. 12, pp. 2586-2592, Dec. 2005, https://doi.org/10.1021/nl052038l.

72. N. C. Seeman, "Nanomaterials Based on DNA," Annu. Rev. Biochem., vol. 79, pp. 65-87, 2010, https:/doi.org/10.1146/annurev-biochem-060308-102244

73. A. W. Knoll et al., "Probe-based 3-D nanolithography using self-amplified depolymerization polymers," Adv. Mater., vol. 22, no. 31, pp. 3361-3365, 2010,

https://doi.org/10.1002/adma.200904386.

74. "IBM Creates Nano-sized 3D Map of Earth in Less Than 3 Minutes!" https://singularityhub. com/2010/04/28/ibm-creates-nano-sized-3dmap-of-earth-in-less-than-3-minutes-video/ (accessed Nov. 29, 2020).

75. "2014 National Nanotechnology Initiative Strategic Plan," 2014. Accessed: Nov. 29, 2020. [Online]. Available: www.whitehouse.gov/administration/ eop/ostp/nstc.

76. "Progress Review on the Coordinated Implementation of the National Nanotechnology Initiative 2011, Environmental, Health and Safety Research Strategy," 2011. Accessed: Nov. 29, 2020. [Online]. Available: www.nano.gov.

77. "Nanoscience and nanotechnologies: opportunities and uncertainties," 2004. Accessed: Nov. 29, 2020. [Online]. Available: https://royalsociety.org/ /media/Royal_Society_Content/policy/ publications/2004/9693.pdf.

78. "Towards a European Strategy for Nanotechnology," 2004. Accessed: Nov. 29, 2020. [Online]. Available: https://ec.europa.eu/research/industrial_technologies/pdf/policy/nano_com_en_new. pdf.

79. "Benefits and Applications | nano.gov." https:// www.nano.gov/you/nanotechnology-benefits (accessed Nov. 29, 2020).

80. L. Van Langenhove, C. Hertleer, P. Westbroek, and J. Priniotakis, "Textile sensors for healthcare," in Smart textiles for medicine and healthcare: Materials, systems and applications, Elsevier Ltd, 2007, pp. 106-122.

https://doi.org/10.1533/9781845692933.1.106

81. A. Hatamie et al., "Review-Textile Based Chemical and Physical Sensors for Healthcare Monitoring," J.
Electrochem. Soc., vol. 167, no. 3, p. 037546, Jan. 2020, https://doi.org/10.1149/1945-7111/ab6827.

82. P. J. Lu, S. C. Huang, Y. P. Chen, L. C. Chiueh, and D. Y. C. Shih, "Analysis of titanium dioxide and zinc oxide nanoparticles in cosmetics," J. Food Drug Anal., vol. 23, no. 3, pp. 587-594, Sep. 2015, https://doi.org/10.1016/j.jfda.2015.02.009.

83. C. S. Thaxton, D. G. Georganopoulou, and C. A. Mirkin, "Gold nanoparticle probes for the detection of nucleic acid targets," Clinica Chimica Acta, vol. 363, no. 1-2. Elsevier, pp. 120-126, Jan. 01, 2006,

https://doi.org/10.1016/j.ccen.2005.05.042.

84. J. B. Vines, J. H. Yoon, N. E. Ryu, D. J. Lim, and H. Park, "Gold nanoparticles for photothermal cancer therapy," Frontiers in Chemistry, vol. 7, no. APR. Frontiers Media S.A., p. 167, 2019, https://doi.org/10.3389/fchem.2019.00167.

85. A. Meola, J. Rao, N. Chaudhary, M. Sharma, and S. D. Chang, "Gold nanoparticles for brain tumor imaging: A systematic review," Frontiers in Neurology, vol. 9, no. MAY. Frontiers Media S.A., May 14, 2018, https://doi.org/10.3389/fneur.2018.00328.

86. S. Bagheri et al., "Using gold nanoparticles in diagnosis and treatment of melanoma cancer," Artificial Cells, Nanomedicine and Biotechnology, vol. 46, no. sup1. Taylor and Francis Ltd., pp. 462-471, Oct. 31, 2018, https://doi.org/10.1080/21691401.2018.1430585.

87. J. Chen, X. Zhang, R. Millican, J. E. Creutzmann, S. Martin, and H. W. Jun, "High density lipoprotein mimicking nanoparticles for atherosclerosis," Nano Convergence, vol. 7, no. 1. Korea Nano Technology Research Society, Dec. 01, 2020, https://doi.org/10.1186/s40580-019-0214-1.

88. F. U. Din et al., "Effective use of nanocarriers as drug delivery systems for the treatment of selected tumors," International Journal of Nanomedicine, vol. 12. Dove Medical Press Ltd., pp. 7291-7309, Oct. 05, 2017, https://doi.org/10.2147/IJN.S146315.

89. M. Griffin, D. Kalaskar, A. Seifalian, and P. Butler, "An update on the Application of Nanotechnology in Bone Tissue Engineering," Open Orthop. J., vol. 10 , no. 1 , pp. $836-848$, Jan. 2017 , https://doi.org/10.2174/1874325001610010836.

90. R. Medhi, P. Srinoi, N. Ngo, H. V. Tran, and T. R. Lee, "Nanoparticle-Based Strategies to Combat COVID-19," ACS Applied Nano Materials, vol. 3, no. 9. American Chemical Society, pp. 8557-8580, Sep. 25, 2020,

https://doi.org/10.1021/acsanm.0c01978.

91. M. Hellfritzsch and R. Scherließ, "Mucosal vaccination via the respiratory tract," Pharmaceutics, vol. 11, no. 8. MDPI AG, Aug. 01, 2019, https://doi.org/10.3390/pharmaceutics 11080375. 
92. U. J. Etim, P. Bai, and Z. Yan, "Nanotechnology Applications in Petroleum Refining," in Saleh T. (eds) Nanotechnology in Oil and Gas Industries. Topics in Mining, Metallurgy and Materials Engineering, Springer, Cham, 2018, pp. 37-65. https://doi.org/10.1007/978-3-319-60630-9 2

93. H. Soukht Saraee, S. Jafarmadar, H. Taghavifar, and S. J. Ashrafi, "Reduction of emissions and fuel consumption in a compression ignition engine using nanoparticles," Int. J. Environ. Sci. Technol., vol. 12, no. 7, pp. 2245-2252, Jul. 2015, https://doi.org/10.1007/s13762-015-0759-4.

94. F. Su, C. Lu, W. Cnen, H. Bai, and J. F. Hwang, "Capture of $\mathrm{CO} 2$ from flue gas via multiwalled carbon nanotubes," Sci. Total Environ., vol. 407, no. 8, pp. 3017-3023, Apr. 2009,

https://doi.org/10.1016/j.scitotenv.2009.01.007.

95. A. Lekawa-Raus, J. Patmore, L. Kurzepa, J. Bulmer, and K. Koziol, "Electrical properties of carbon nanotube based fibers and their future use in electrical wiring," Adv. Funct. Mater., vol. 24, no. 24, pp. 3661-3682, Jun. 2014, https://doi.org/10.1002/adfm.201303716.

96. S. Boncel, A. Kolanowska, A. W. Kuziel, and I. Krzyżewska, "Carbon Nanotube Wind Turbine Blades: How Far Are We Today from Laboratory Tests to Industrial Implementation?", ACS Appl. Nano Mater., vol. 1, no. 12 , pp. 6542-6555, Dec. 2018,

https://doi.org/10.1021/acsanm.8b01824.

97. M. Jošt, L. Kegelmann, L. Korte, and S. Albrecht, "Monolithic Perovskite Tandem Solar Cells: A Review of the Present Status and Advanced Characterization Methods Toward 30\% Efficiency," Advanced Energy Materials, vol. 10, no. 26. Wiley-VCH Verlag, Jul. 01, 2020, https://doi.org/10.1002/aenm.201904102.

98. M. I. Nugraha et al., "Low-Temperature-Processed Colloidal Quantum Dots as Building Blocks for Thermoelectrics," Adv. Energy Mater., vol. 9, no. 13, p. 1803049, Apr. 2019, https://doi.org/10.1002/aenm.201803049.

99. M. Jošt et al., "Textured interfaces in monolithic perovskite/silicon tandem solar cells: advanced light management for improved efficiency and energy yield," Energy Environ. Sci, vol. 11, p. 3511, 2018,

https://doi.org/10.1039/c8ee02469c.

100. I. S. Yunus, Harwin, A. Kurniawan, D. Adityawarman, and A. Indarto, "Nanotechnologies in water and air pollution treatment," Environ. Technol. Rev., vol. 1, no. 1, pp. 136-148, Nov. 2012, https://doi.org/10.1080/21622515.2012.733966.

101. M. Heiranian, A. B. Farimani, and N. R. Aluru, "Water desalination with a single-layer MoS 2 nanop- ore," Nat. Commun., vol. 6, 2015,

https://doi.org/10.1038/ncomms9616.

102. B. I. Kharisov, H. V. R. Dias, and O. V. Kharissova, "Nanotechnology-based remediation of petroleum impurities from water," J. Pet. Sci. Eng., vol. 122, pp. 705-718, Aug. 2014, https://doi.org/10.1016/j.petrol.2014.09.013.

103. E. Akbari et al., "Analytical calculation of sensing parameters on carbon nanotube based gas sensors," Sensors (Switzerland), vol. 14, no. 3, pp. 5502-5515, Mar. 2014, https://doi.org/10.3390/s140305502.

104. M. Shafique and X. Luo, "Nanotechnology in transportation vehicles: An overview of its applications, environmental, health and safety concerns," Materials, vol. 12, no. 15. MDPI AG, Aug. 01, 2019, https://doi.org/10.3390/ma12152493.

105. S. E. O and D. B. Smith, "Potential Impact of Carbon Nanotube Reinforced Polymer Composite on Commercial Heavy Aircraft," 2004. Accessed: Nov. 29, 2020. [Online]. Available: https://apps.dtic. mil/sti/pdfs/AD1106874.pdf.

106. L. Mardare and L. Benea, "Development of Anticorrosive Polymer Nanocomposite Coating for Corrosion Protection in Marine Environment," in IOP Conference Series: Materials Science and Engineering, Jun. 2017, vol. 209, no. 1, p. 47, https://doi.org/10.1088/1757-899X/209/1/012056.

107. I. Ahmed, N. Ahmad, I. Mehmood, I. U. Haq, M. Hassan, and M. U. A. Khan, "Applications of Nanotechnology in Transportation Engineering," in Advanced Research on Nanotechnology for Civil Engineering Applications, IGI Global, 2016, pp. 180-207. https://doi.org/10.4018/978-1-5225-0344-6.ch006

108. W. Zhu, P. J. M. Bartos, and A. Porro, "Application of nanotechnology in construction," Mater. Struct., vol. 37, no. 9, pp. 649-658, Nov. 2004, https://doi.org/10.1007/bf02483294.

109. A. Tabaković and E. Schlangen, "Self-healing technology for asphalt pavements," in Advances in Polymer Science, vol. 273, Springer New York LLC, 2016, pp. 285-306. https://doi.org/10.1007/12 2015 335

110. M. Barriera, S. Pouget, B. Lebental, and J. Van Rompu, "In situ pavement monitoring: A review," Infrastructures, vol. 5, no. 2. MDPI Multidisciplinary Digital Publishing Institute, 2020, https://doi.org/10.3390/infrastructures5020018.

111. "Infineon Unveils World's Smallest Nanotube Transistor - Infineon Technologies." https://www. infineon.com/cms/en/about-infineon/press/market-news/2004/132191.html (accessed Dec. 22, 2020). 
112. G. Hills et al., "Modern microprocessor built from complementary carbon nanotube transistors," Nature, vol. 572, pp. 595-602, 2019, https://doi.org/10.1038/s41586-019-1493-8.

113. M. M. Shulaker et al., "Carbon nanotube computer," Nature, vol. 501, no. 7468, pp. 526-530, Sep. 2013, https://doi.org/10.1038/nature12502.

114. E. Gibney, "Biggest carbon-nanotube chip yet says 'Hello, World!,' Nature, 2019, https://doi.org/10.1038/d41586-019-02576-7.

115. B. Gervasi, "Will Carbon Nanotube Memory Replace DRAM?," IEEE Micro, vol. 39, no. 2, pp. 45-51, 2019, https://doi.org/10.1109/MM.2019.2897560.

116. "Image Gallery - Nantero.com." http://nantero. com/newsroom/press-image-gallery/\#lightbox/ 5/ (accessed Dec. 22, 2020).

117. M. Devoret and C. Glattli, "Single-electron transistors," Phys. World, vol. 11, no. 9, pp. 29-33, Sep. 1998, https://doi.org/10.1088/2058-7058/11/9/26.

118. "File:Set schematic.svg - Wikimedia Commons." https://commons.wikimedia.org/wiki/File:Set_ schematic.svg (accessed Nov. 29, 2020).

119. O. Kumar and M. Kaur, "Single Electron Transistor: Applications \& Problems," Int. J. VLSI Des. Commun. Syst., vol. 1, no. 4, pp. 24-29, Dec. 2010, https://doi.org/10.5121/vlsic.2010.1403.

120. S. Bhatti, R. Sbiaa, A. Hirohata, H. Ohno, S. Fukami, and S. N. Piramanayagam, "Spintronics based random access memory: a review," Materials Today, vol. 20, no. 9. Elsevier B.V., pp. 530-548, Nov. 01, 2017, https://doi.org/10.1016/j.mattod.2017.07.007.

121. "File:Spin-valve GMR.svg - Wikimedia Commons." https://commons.wikimedia.org/wiki/File:Spinvalve_GMR.svg (accessed Nov. 29, 2020).

122. J. G. Webster, S. Z. Peng, Y. Zhang, M. X. Wang, Y. G. Zhang, and W. Zhao, "Magnetic Tunnel Junctions for Spintronics: Principles and Applications," in Wiley Encyclopedia of Electrical and Electronics Engineering, John Wiley \& Sons, Inc., 2014, pp. 1-16. https://doi.org/10.1002/047134608X.W8231

123. V. Sverdlov, J. Weinbub, and S. Selberherr, "Spintronics as a Non-Volatile Complement to Modern Microelectronics," Inf. MIDEM, vol. 47, no. 4, pp. 195-210, 2017.

124. M. Wang, Y. Zhang, X. Zhao, and W. Zhao, "Tunnel Junction with Perpendicular Magnetic Anisotropy: Status and Challenges," Micromachines, vol. 6, no. 8, pp. 1023-1045, 2015, https://doi.org/10.3390/mi6081023.

125. J. J. Yang, M. D. Pickett, X. Li, D. A. A. Ohlberg, D. R. Stewart, and R. S. Williams, "Memristive switching mechanism for metal/oxide/metal nanodevices,"
Nat. Nanotechnol., vol. 3, no. 7, pp. 429-433, 2008, https://doi.org/10.1038/nnano.2008.160.

126. N. Samardzic, B. Bajac, V. V Srdic, and G. M. Stojanovic, "Conduction Mechanisms in Multiferroic Multilayer BaTiO3/NiFe2O4/BaTiO3 Memristors," J. Electron. Mater., vol. 46, no. 10, pp. 5492-5496, 2017, https://doi.org/10.1007/s11664-017-5618-2.

127. Y. Lu, A. Alvarez, C. H. Kao, J. S. Bow, S. Y. Chen, and I. W. Chen, "An electronic silicon-based memristor with a high switching uniformity," Nat. Electron., vol. 2, no. 2, pp. 66-74, Feb. 2019, https://doi.org/10.1038/s41928-019-0204-7.

128. T. Fu et al., "Bioinspired bio-voltage memristors," Nat. Commun., vol. 11, no. 1, pp. 1-10, 2020, https://doi.org/10.1038/s41467-020-15759-y.

129. Z. Wang et al., "Memristors with diffusive dynamics as synaptic emulators for neuromorphic computing," Nat. Mater., vol. 16, no. 1, pp. 101-108, Jan. 2017, https://doi.org/10.1038/nmat4756.

130. L. Shi, G. Zheng, B. Tian, B. Dkhil, and C. Duan, "Research progress on solutions to the sneak path issue in memristor crossbar arrays," Nanoscale Advances, vol. 2, no. 5. Royal Society of Chemistry, pp. 1811-1827, May 01, 2020, https://doi.org/10.1039/d0na00100g.

131. S. Pi et al., "Memristor crossbar arrays with 6-nm half-pitch and 2-nm critical dimension," Nat. Nanotechnol., vol. 14, pp. 35-39, 2019, https://doi.org/10.1038/s41565-018-0302-0.

132. N. Samardžić, M. Mionić, B. Dakić, H. Hofmann, S. Dautović, and G. Stojanović, "Analysis of quantized electrical characteristics of microscale $\mathrm{TiO} 2$ ink-jet printed memristor," IEEE Trans. Electron Devices, vol. 62, no. 6, pp. 1898-1904, Jun. 2015, https://doi.org/10.1109/TED.2015.2421283.

133. S. Stathopoulos et al., "Multibit memory operation of metal-oxide Bi-layer memristors," Sci. Rep., vol. 7, 2017, https://doi.org/10.1038/s41598-017-17785-1.

134. T. F. Schranghamer, A. Oberoi, and S. Das, "Graphene memristive synapses for high precision neuromorphic computing," Nat. Commun., vol. 11, 2020, https://doi.org/10.1038/s41467-020-19203-z.

135. "Nanotechnology: the invisible giant tackling Europe's future challenges." 2013, Accessed: Mar. 01, 2021. [Online]. Available: https://ec.europa.eu/ research/industrial_technologies/pdf/nanotechnology_en.pdf.

136. M. Kadunc and N. Bruno, "Keeping our eyes on the Horizon; Monitoring flash series: a Horizon 2020 monitoring report," 2020. https://doi.org/10.2777/303024. 
137. "Horizon 2020; Nanotechnologies, Advanced Materials, Biotechnology and Advanced Manufacturing and Processing; Work Programme 2018-2020," 2020. Accessed: Mar. 01, 2021. [Online]. Available: https://ec.europa.eu/research/participants/data/ ref/h2020/wp/2018-2020/main/h2020-wp1820leit-nmp_en.pdf.

138. "Graphene research, innovation and collaboration | Graphene Flagship." https://graphene-flagship.eu/ (accessed Mar. 01, 2021).

139. "Quantum Technology | The future is Quantum." https://qt.eu/ (accessed Mar. 01, 2021).

140. "EU budget: Commission proposes most ambitious Research and Innovation programme yet." 2018, [Online]. Available: https://ec.europa.eu/ commission/presscorner/detail/en/IP_18_4041.

141. R. Schreiber, "Wafer-Scale Processors: The Time Has Come - Cerebras," 2019. https://cerebras.net/ wafer-scale-processors-the-time-has-come/ (accessed Apr. 01, 2021).

142. B. Solca, "Cerebras breaks trillion transistor count with chip larger than an iPad - NotebookCheck. net News," 2019. https://www.notebookcheck. net/Cerebras-breaks-trillion-transistor-countwith-chip-larger-than-an-iPad.431193.0.html (accessed Apr. 01, 2021).

143. "Home-Cerebras." https://cerebras.net/ (accessed Apr. 01, 2021).

144. R. Thubron, "Cerebras reveals details of the world's largest chip: 2.6 trillion transistors, 850,000 cores | TechSpot," 2020. https://www.techspot.com/ news/86427-cerebras-reveals-details-world-largest-chip-26-trillion.html (accessed Apr. 01, 2021).

145. N. Nasiri and C. Clarke, "Nanostructured Chemiresistive Gas Sensors for Medical Applications," Sensors, vol. 19, no. 3, p. 462, Jan. 2019, https://doi.org/10.3390/s19030462.

146. C. Wilson, "Quantum dots in brain could treat Parkinson's disease," New Sci., no. 3186, 2018.

147. D. Kim et al., "Graphene quantum dots prevent a-synucleinopathy in Parkinson's disease," Nat. Nanotechnol., vol. 13, no. 9, pp. 812-818, Sep. 2018, https://doi.org/10.1038/s41565-018-0179-y.
148. Y. Liu, L. P. Xu, W. Dai, H. Dong, Y. Wen, and X. Zhang, "Graphene quantum dots for the inhibition of $\beta$ amyloid aggregation," Nanoscale, vol. 7, no. 45, pp. 19060-19065, Dec. 2015, https://doi.org/10.1039/c5nr06282a.

149. A. Al-Ashouri et al., "Conformal monolayer contacts with lossless interfaces for perovskite single junction and monolithic tandem solar cells," Energy Environ. Sci., vol. 12, no. 11, pp. 3356-3369, Nov. 2019, https://doi.org/10.1039/c9ee02268f.

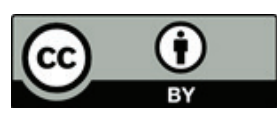

Copyright ( 2021 by the Authors. This is an open access article distributed under the Creative Commons Attribution (CC BY) License (https://creativecommons.org/licenses/by/4.0/), which permits unrestricted use, distribution, and reproduction in any medium, provided the original work is properly cited.

Arrived: 29. 12. 2020

Accepted: 07. 04. 2021 